\title{
Article \\ Quantification of the Absorption and Scattering Effects of Diffusers in a Room with Absorbent Ceiling
}

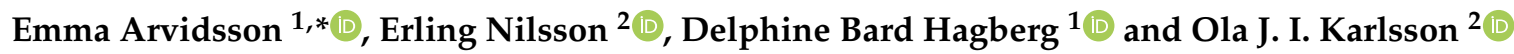 \\ 1 Division of Engineering Acoustics, Lund University, John Ericssons väg 1, 22363 Lund, Sweden; \\ Delphine.Bard@construction.lth.se \\ 2 Saint-Gobain Ecophon AB, Yttervägen 1, 26575 Hyllinge, Sweden; erling.nilsson@ecophon.se (E.N.); \\ ola.karlsson@ecophon.se (O.J.I.K.) \\ * Correspondence: emma.arvidsson@construction.lth.se
}

Citation: Arvidsson, E.; Nilsson, E.; Bard Hagberg, D.; Karlsson, O.J.I.

Quantification of the Absorption and Scattering Effects of Diffusers in a Room with Absorbent Ceiling.

Buildings 2021, 11, 612 .

https://doi.org/10.3390/

buildings11120612

Academic Editor: Francesco Nocera

Received: 22 October 2021

Accepted: 1 December 2021

Published: 4 December 2021

Publisher's Note: MDPI stays neutral with regard to jurisdictional claims in published maps and institutional affiliations.

Copyright: (c) 2021 by the authors. Licensee MDPI, Basel, Switzerland. This article is an open access article distributed under the terms and conditions of the Creative Commons Attribution (CC BY) license (https:// creativecommons.org/licenses/by/ $4.0 /)$.

\begin{abstract}
In ordinary public rooms, such as classrooms and offices, an absorbent ceiling is the typical first acoustic action. This treatment provides a good acoustic baseline. However, an improvement of specific room acoustic parameters, operating for specific frequencies, can be needed. It has been seen that diffusing elements can be effective additional treatment. In order to choose the right design, placement, and quantity of diffusers, a model to estimate the effect on the acoustics is necessary. This study evaluated whether an SEA model could be used for that purpose, particularly for the cases where diffusers are used in combination with an absorbent ceiling. It was investigated whether the model could handle different quantities of diffusing elements, varied diffusion characteristics, and varied installation patterns. It was found that the model was sensitive to these changes, given that the output from the model in terms of acoustic properties will be reflected by the change of diffuser configuration design. It was also seen that the absorption and scattering of the diffusers could be quantified in a laboratory environment: a reverberation chamber. Through the SEA model, these quantities could be transformed to a full-scale room for estimation of the room acoustic parameters.
\end{abstract}

Keywords: absorbers; diffusers; room acoustic design; room acoustic parameters; scattering

\section{Introduction}

In ordinary public rooms such as classrooms and offices, a satisfactory room acoustic environment is critical. It will affect the performance of cognitive tasks and have an impact on hearing and speech in that both listeners and speakers will be affected and, in addition, it also relates to people's well-being. In previous articles [1,2] from this research group, the effect of different room acoustic treatments in ordinary rooms has been studied. Both the effect on room acoustic parameters [1] and the effect on subjective experience [2] have been investigated. In these studies, it was found that diffusers can be a convenient treatment in addition to a sound-absorbing ceiling. An absorbent ceiling is a typical acoustic treatment in this type of room. However, due to the non-uniform distribution of the absorption, the effects of sound spreading interior fittings such as furniture or other diffusing objects are significant and have to be accounted for in the acoustical design. The directional characteristics of sound diffusing elements is a property that is hard to incorporate in today's simulation software. As has been shown in previous papers [1], this is an effect that can be used to fine tune the acoustical conditions. The aim of this paper is to present and evaluate a method of quantifying the sound-spreading effect of objects in rooms with absorbent ceilings. The method is emanating from the SEA model presented in [3]. Basically, a measure is introduced that quantifies the sound energy transfer between the two subsystems used in the SEA model and referred to as the grazing and non-grazing group. The sensitivity of the quantification parameter, denoted equivalent scattering absorption area $A_{s c}$, for different sound spreading configurations is analyzed. A novel method for measuring this parameter in a laboratory set-up is also suggested and exemplified. 
The acoustic environment of a room is highly dependent on the sound reflections in the room. As far back as 1964, Lochner and Burger [4] showed the importance of early reflections in rooms used for speech and how the ratio of early reflections will affect the subjective experience. The early reflections will contribute to the direct sound. In a study by Bradley et al. [5], the authors recommended focusing on increasing the early reflections rather than lowering the reverberation time in rooms used for speech. The importance of early reflections and their relation to subjective impression has been further investigated in several studies [6-10]. Puglisi et al. examined the effect of early reflections on cognitive skills by studying the reading speed of Italian second graders, finding a correlation to $C_{50}$ but not, however, to reverberation time [11]. It has also been shown by Bradley and Reich [12] that $C_{50}$ to some extent can complement a low $\mathrm{S} / \mathrm{N}$ ratio. In several of the abovementioned references, the importance of considering several room acoustical parameters in acoustic design is raised. Sound strength, $G$, a parameter describing how the room responds to the sound energy emitted from a sound source, is normally used in the acoustic design of performance spaces [13-15].

In terms of cognitive skills, the acoustic environment is critical. It is well known that noise disturbs concentration, but room acoustic properties will also affect the ability to perform complex tasks. In [16-18], different acoustic conditions were evaluated in relation to cognitive skills, showing for example how the ability to recall words is affected when the reverberation time is longer or the background noise higher. An unsatisfactory sound environment can cause a more demanding interpretation and processing of words, even if the words are correctly recalled. Thereby, it is of great importance to ensure good acoustics in these room, and to do so, appropriate acoustic treatment is necessary.

To adjust the above-mentioned acoustic parameters and create a satisfactory sound environment for the performance of cognitive skills, different types of acoustic treatments can be used. At present, it is typical for ordinary rooms to use porous absorbers. The placement of such treatment is important as regards the effect on different room acoustical parameters $[19,20]$. Furthermore, the absorption coefficients are also angle dependent, and methods have been developed to take this into account on a laboratory scale [21]. Nolan et al. worked on a measurement method for in situ measurement of angle-dependent absorption [22,23].

Environments where high effort is dedicated to the acoustics include performance spaces, such as concert halls and theatres. A typical acoustic treatment in these environments is the use of diffusers. This is based on the need to avoid flutter echoes, support the artist, and ensure everyone in the audience has a favorable acoustic experience [24]. The same types of acoustic challenges can be found in ordinary public rooms such as classrooms and offices, but instead of voice support for a performing artist, it can be a teacher that needs voice support. Furthermore, it is critical that the students can hear information properly. Choi has investigated the combination of absorbers and diffusers in a small-scale model, studying the effect on different acoustic properties [25-28]. The placement of absorbers and diffusers on walls was investigated in [29].

The effect on different room acoustic measurements was evaluated in full scale in the first step of this study, showing how different treatments can be used depending on different acoustic requirements [1]. It was shown how diffusers can be used to effectively improve speech clarity and reverberation time while maintaining the sound energy, G, in the room. Using the diffusers in the ceiling gave significant results in terms of $C_{50}$ at the back of the room, with a difference of $3 \mathrm{~dB}$ for octave $1000 \mathrm{~Hz}$. According to ISO 3382-1 [30], the just-noticeable difference, JND, for this parameter is $1 \mathrm{~dB}$, with the first part of this standard being dedicated to performance spaces. However, the just-noticeable difference for speech was investigated by Bradley and Reich, showing that larger differences, such as up to $3 \mathrm{~dB}$, are needed for a sustainable improvement in the room [31]. Visentin et al. investigated the perception of a diffuse versus a specular reflection, showing that diffuse reflections were preferable and made speech clearer [32]. Shtrepi et al. [33] investigated the 
effect of the location of diffusers as well as the distance from those from both objective and subjective aspects [34,35].

It has been shown that rooms with an acoustic ceiling will not have a diffuse sound field, and the decay will not be linear. As a consequence of this, calculation in accordance with diffuse sound field theory will not be appropriate for these types of rooms. With the aim of accounting for the circumstances of the sound field in a room with an absorbent ceiling, a calculation model has been developed [3]. The model is based on statistical energy analysis, SEA, and the theory of SEA is explained in [36]. SEA models are convenient for use as prediction models on a system level [37]. The SEA model referred to above has been shown to provide better predictions than models that assume diffuse conditions [38].

\section{Study Objective and Principal Conclusion}

Previous studies have shown how diffusers can contribute to the fine tuning of the acoustics in ordinary rooms and, further, how diffusers could provide a more uniform subjective experience of the acoustic environment [1,2]. For the use of diffusers in such rooms, it is necessary to have a model to estimate the acoustic effect that the treatment will provide. Such a model has been investigated in this study.

The model used is an SEA (statistical energy analysis) model, which been developed particularly for rooms with absorbent ceilings [3]. It was investigated whether this model is sensitive enough to be applicable to a variation of diffuser set-ups. From a number of configurations involving different quantities of diffusers, different diffuser characteristics, and different installation patterns, the model's sensitivity was evaluated. These experiments were performed in a full-scale room. The evaluation showed that a parameter denoted $A_{s c}$, equivalent absorption scattering area, could be related to the different set-ups of diffusers. This parameter, $A_{s c}$, is used as input parameter in the SEA model to calculate the acoustic properties.

Accordingly, in order to use the SEA model for estimation of the acoustic properties, the $A_{s c}$ for an element must be known. It was investigated whether quantification in terms of $A_{s c}$ could be made at a smaller scale. Comparison of the $A_{s c}$ obtained in the full-scale room and the smaller scale showed similar values. Thus, this way of quantifying diffusers is suggested as a method to quantify diffusers for ordinary rooms.

\section{Materials and Methods}

In ordinary rooms such as classrooms and offices, the typical acoustic treatment is an absorbent ceiling. This treatment will affect the sound field in the room by diminishing the diffuse field and enhancing a grazing field with sound waves traveling almost parallel to the ceiling. To consider this sound, wave propagation is critical for accurate room acoustic estimations for these rooms.

Another important aspect to be considered in these rooms is the effect of objects, such as furniture and other interiors. These objects can contribute both absorption and scattering, which will affect the room acoustics. Furthermore, the effect will differ for different frequencies. In the standard EN 12354-6 concerning sound absorption in enclosed spaces, the equivalent absorption area $\left(A_{o b j}\right)$ is accounted for by using the formula $A_{o b j}=V_{o b j}^{2 / 3}[39]$. This formula is to be used in the Sabine formula, which assumes a diffuse sound field.

Since the absorbent ceiling and objects will have a considerable effect on the room acoustic properties in a room, a model developed to account for these two aspects has been applied in this study. The prerequisites and equations for this model are described in the following paragraphs. The complete derivation of the energy model can be found in [3]. Information about experiments and materials used in the study is found below in this chapter.

\subsection{A Statistical Energy Analysis Model for Ordinary Rooms}

The energy model applied in this study has been developed for rooms with an absorbent ceiling. It is assumed that the sound field in these rooms will be a build-up of 
grazing and non-grazing sound waves. In practice, this applies when the mean absorption coefficient for the ceiling is larger than 0.7 for the octave bands $250-4000 \mathrm{~Hz}$ [3]. The grazing sound field accounts for the sound waves propagating almost parallel to the ceiling. The SEA model accounts for these two sound fields by introducing two sub-systems, a grazing and a non-grazing sub-system. Energy can be transferred from the grazing to the non-grazing sub-system. This energy transfer is due to different scattering objects such as furniture [3]. The setup of sub-systems and energy flow is depicted in Figure 1.

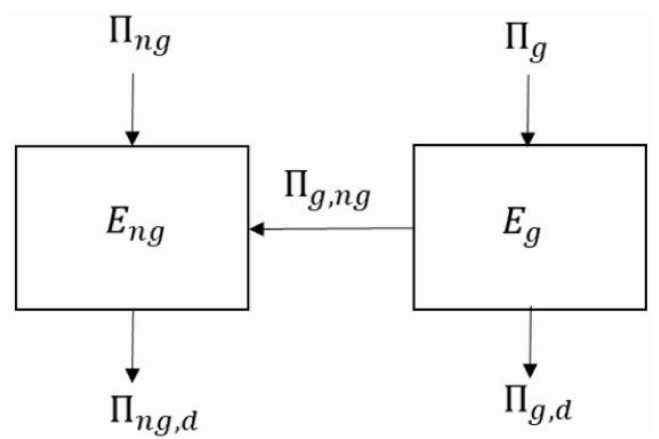

Figure 1. The total energy of each system is denoted $E_{n g}$ and $E_{g}$, where the index " $n g^{\prime \prime}$ refers to non-grazing and " $g$ " refers to grazing. Energy flowing into the system is denoted $\prod_{n g}$ and $\prod_{g}$ and dissipating from the system $\prod_{n g, d}$ and $\prod_{g, d}$. Energy transmitted from the grazing to the non-grazing sub-system is denoted $\prod_{g}, n g$.

The total decay in a room with an absorbent ceiling is built up of grazing and nongrazing modes. In the early part of the decay, the non-grazing modes are dominant. The latter part is dominated by the grazing modes and will mainly determine the reverberation time. The decay is depicted in Figure 2.

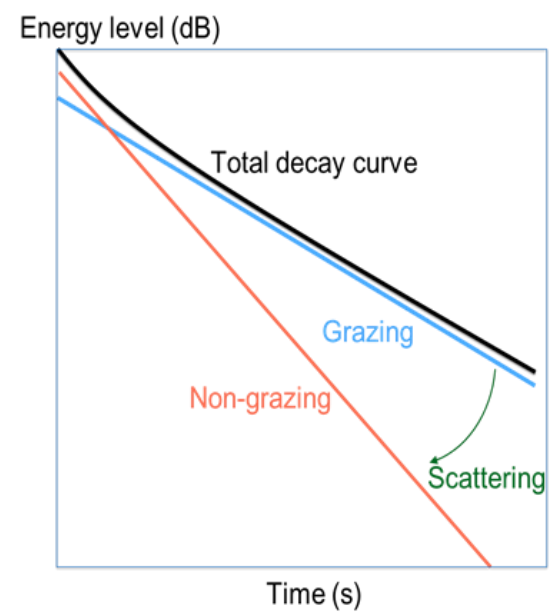

Figure 2. The total decay in a room is the sum of the energy in the grazing and the non-grazing sound fields [40].

The total decay in intensity is given by [3]

$$
I(t)=I_{n g}(0)\left(e^{-13.8 t / T_{n g}}+\frac{T_{g} \Delta N_{g}}{T_{n g} \Delta N_{n g}} e^{-13.8 t / T_{g}}\right)
$$

where

$I_{n g}$ is the intensity in the non-grazing sub-system

$T_{n g}$ is the reverberation time in the non-grazing sub-system, given by Equation (2) below $T_{g}$ is the reverberation time in the grazing sub-system, given by Equation (3) below 
$N_{g}$ is the number of modes in the grazing sub-system

$N_{n g}$ is the number of modes in the non-grazing sub-system

The formula for the reverberation time in the non-grazing sub-system is given by [3]

$$
T_{n g}=\frac{0.161 \mathrm{~V}}{A_{\text {ceiling }}+A_{\text {furniture }}+A_{\text {surface }}+4 m V}
$$

where

$V$ is the volume of the room

$A_{\text {ceiling }}$ is the absorption area of the ceiling in the non-grazing sub-system

$A_{\text {furniture }}$ is the Sabine equivalent absorption area of the furniture

$A_{\text {surface }}$ is the equivalent absorption area of the walls and floor

$4 m V$ is the air absorption, $m$ is the energy attenuation constant in air, and $V$ is the volume of the room.

The formula for the reverberation time in the grazing sub-system has been adapted for a two-dimensional sound field. Furthermore, the equivalent scattering absorption area, $A_{s c}$, has been introduced in this equation. $A_{s c}$ quantifies the effect in terms of absorption and scattering from different objects. The grazing reverberation time is given by [3]

$$
T_{g}=\frac{0.127 V}{A_{g, \text { ceiling }}+A_{s c}+A_{\text {surface }}+\pi m V}
$$

where

$A_{g, c e i l i n g}$ is the absorption area of the ceiling in the grazing sub-system

$A_{s c}$ is the equivalent scattered absorption area (see Equation (4))

$\pi m V$ is the air absorption in the two-dimensional field, the grazing sub-system, $m$ is the energy attenuation constant in air, and $V$ is the volume of the room.

The energy transmitted from the grazing to the non-grazing sub-system is described as the coupling loss factor, which is denoted $\prod_{g, n g}$ in Figure 1 and depicted as scattering in Figure 2. The coupling loss factor can be expressed as an equivalent scattering absorption area $A_{s c}$ [3]. An estimation of $A_{s c}$ for scattering objects is obtained by measuring the reverberation times in rooms with absorbent ceiling treatment with and without objects according to Equation (4) [3].

$$
A_{s c}=0.127 V\left(\frac{1}{T_{20, \text { with }}}-\frac{1}{T_{20, \text { without }}}\right)
$$

where

$V$ is the volume of the room

$T_{20, \text { with }}$ is the reverberation time with objects

$T_{20, \text { without }}$ is the reverberation time without objects

In the study presented in this paper, Equation (4) has been used to calculate the scattering and absorption properties, $A_{s c}$, for diffusers. $T_{20, \text { with }}$ is the reverberation time measured with diffusers (for different configurations, see below).

A prototype of a diffuser was used. The orientation of this diffuser was used in different quantities and patterns in order to evaluate whether $A_{s c}$ would be a measure sensitive enough to reflect how the diffusers affect the room acoustics. The relation between $A_{s c}$ and the room acoustic properties was evaluated and is presented in the Results paragraph below. It was also evaluated whether $A_{s c}$ measured in a full-size classroom and measured on a smaller scale can be related. This was done since it is important that elements such as diffusers can be quantified in a laboratory scale. All the configurations tested, the test environment, and the material properties are presented below in this chapter.

\subsection{Test Environment}

Measurements were conducted in a mock-up of a rectangular classroom with the dimensions $7.32 \times 7.57 \times 3.50 \mathrm{~m}$, see Figure 3 , and in a reverberation chamber with the 
dimensions $3.57 \times 3.99 \times 4.00 \mathrm{~m}$, see Figure 4 . In both cases, the ceiling was installed at a height of $2.70 \mathrm{~m}$ from the floor.

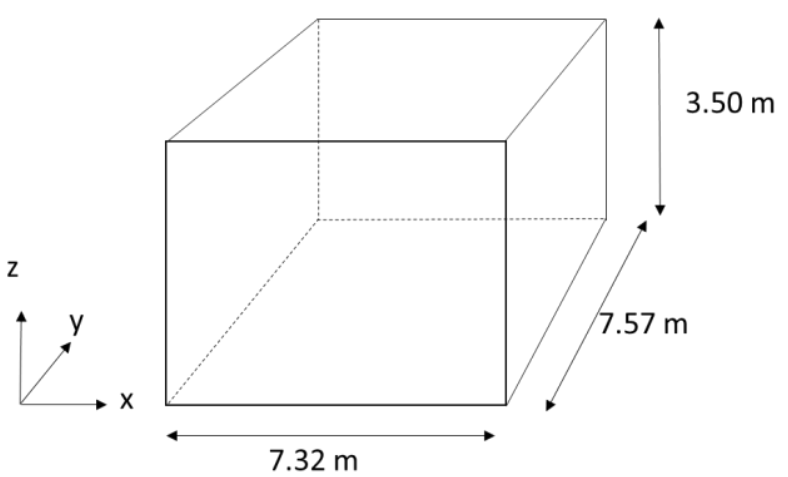

Figure 3. Dimensions of the classroom.

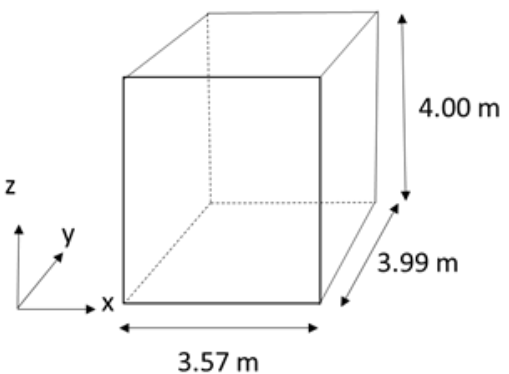

Figure 4. Dimensions of the reverberation chamber.

All measurements were performed over a two-day period. The mock-up was located in a laboratory environment where the humidity and temperature were controlled and kept constant. The background noise level was $<30 \mathrm{~dB}(\mathrm{~A})$.

In cases that included furniture (classroom mock-up), eleven tables and eighteen slightly upholstered chairs were used. The furnished room is depicted in Figures 1 and 5.

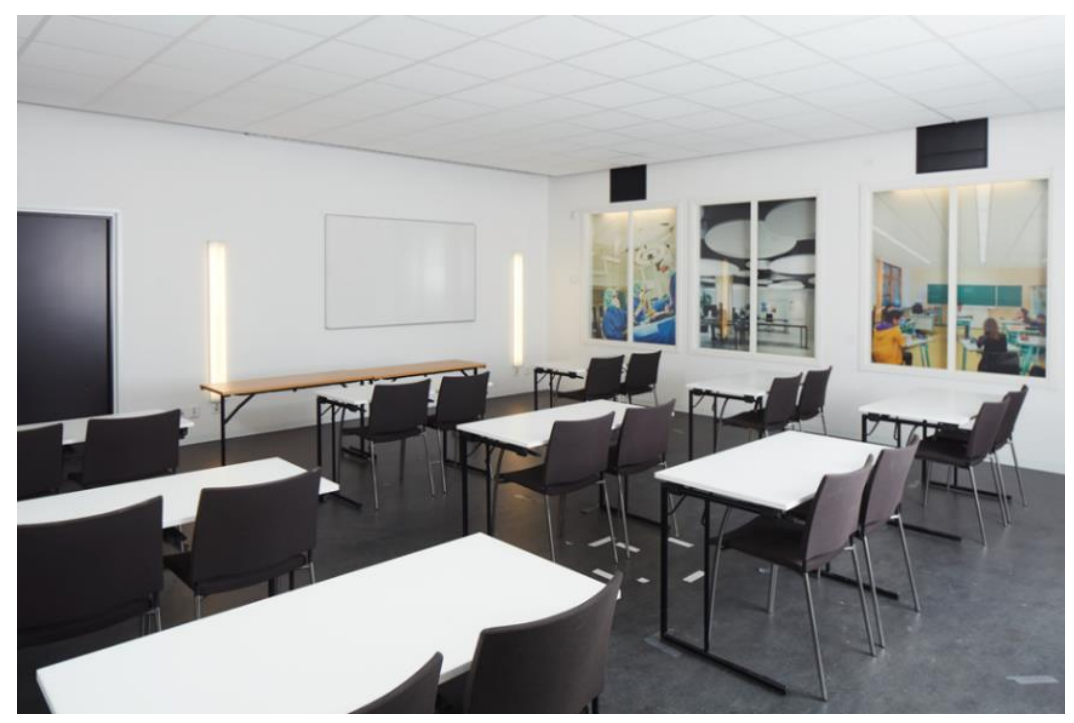

Figure 5. The mock-up classroom with furniture.

These furnishings contributed to a small amount of absorption at the higher frequencies and scattering at mid-frequencies. Absorption properties were evaluated according to diffuse sound field theory, Sabine, from measurements when only furniture was placed in 
the classroom, with no absorbent ceiling. Without a ceiling, it has been assumed that the sound field is diffuse, and therefore, the Sabine formula is used in this case. The absorption properties and equivalent scattering absorption area, i.e., both absorption and scattering from the furniture, were calculated using Equation (4). The absorption and scattering from the furniture can be found in Figure 6.

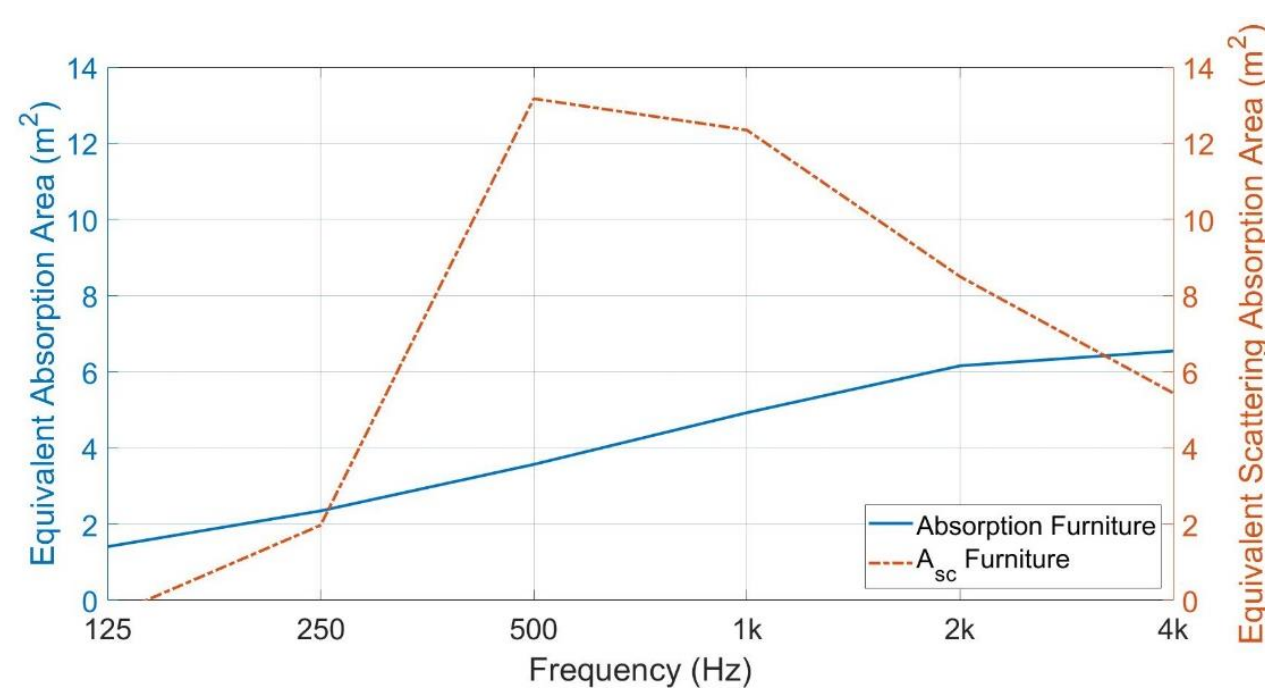

Figure 6. Absorption and equivalent scattering absorption area, $A_{s c}$, from the furniture. The furniture contributes to absorption in the higher frequency range and scattering at the mid-frequencies.

\subsection{Acoustic Treatment}

Porous absorbers and diffusers were used in the study. Their material properties are described in the following paragraphs.

\subsubsection{Porous Absorbers}

The porous absorbers used were a commercial product made of glass wool. The thickness of the product was $40 \mathrm{~mm}$, and its air flow resistivity was $40 \mathrm{kPas} / \mathrm{m}^{2}$, which was measured in accordance with ISO 9053-2 [41]. The measurement of the absorption properties for this product was performed according to ISO 354 [42] with the measurement made at an overall depth of the system (ODS) of $200 \mathrm{~mm}$ and was further evaluated according to ISO 11654 [43]. The weighted absorption coefficient $\alpha_{w}$ is equal to 1 . The sketch up ODS set up for a $40 \mathrm{~mm}$ product can be seen in Figure 7.

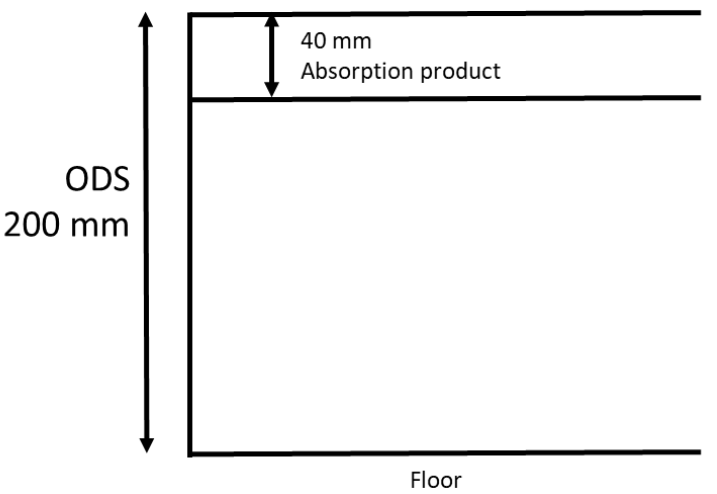

Figure 7. Sketch of mounting system for overall depth (ODS) of the system of $200 \mathrm{~mm}$.

The sound absorbing tiles were in modules measuring $600 \mathrm{~mm} \times 600 \mathrm{~mm}$. When installed in the ceiling, they covered an area of approximately $52 \mathrm{~m}^{2}$. 


\subsubsection{Diffusers}

The term diffuser is not clearly defined in the literature. The elements used in this case contribute to the dispersion of reflections in different ways, such as spatial dispersion and scattering as well as diffraction. Altogether, the elements contribute to a more diffuse sound field and are thus called diffusers in this study.

The diffusers used were prototypes made of wood, with a timber frame and a surface covered with hardboard material. The module size was $600 \mathrm{~mm} \times 600 \mathrm{~mm}$, maximum depth $100 \mathrm{~mm}$. See the sketch in Figure 8.

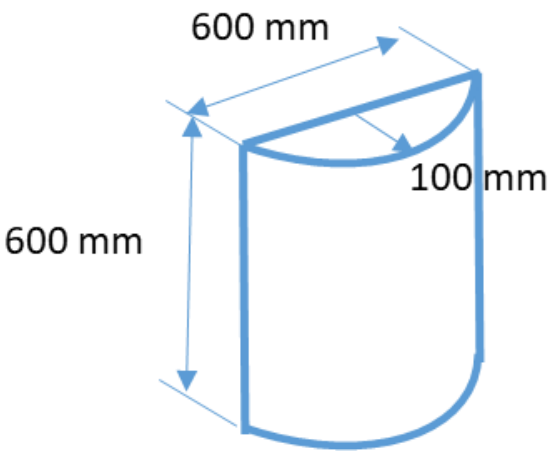

Figure 8. Sketch with dimensions of the diffusers used in the study.

The diffusers were mounted in two different orientations, vertical and horizontal. With vertically oriented diffusers, most of the sound waves reflected in a vertical, z-direction, while with horizontally oriented diffusers, most of the sound waves reflected in a horizontal, x-direction. A description of prototypes mounted vertically can be found in Figure 9, and those mounted horizontally can be found in Figure 10.

The diffusion characteristics for the frequencies were measured in a semi-anechoic chamber. An impulse response was used, the energy was measured in the reflections, and direct sound was removed. The reflections for every 10 degrees from 0 to 90 degrees were measured. The characteristics for the vertically oriented and for the horizontally oriented diffusers and for a flat panel were evaluated. The results for $500 \mathrm{~Hz}, 2000 \mathrm{~Hz}$, and $4000 \mathrm{~Hz}$ are presented in Figure 11.

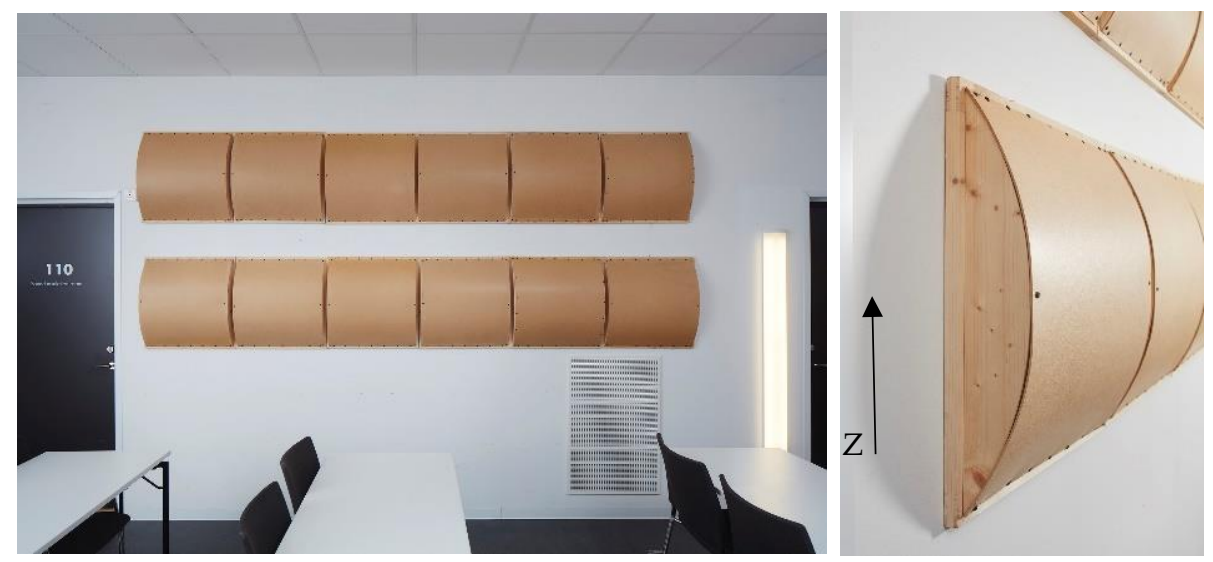

Figure 9. Diffuser vertically oriented; most sound waves are reflected in the vertical direction. 

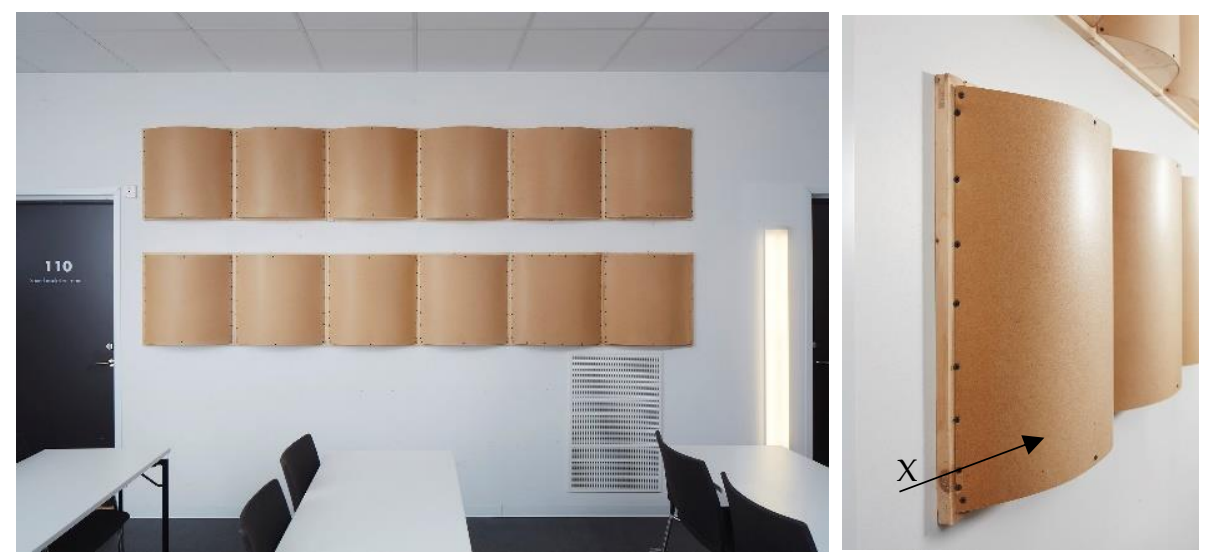

Figure 10. Diffuser horizontally oriented; most sound waves are reflected in the horizontal direction.

(a)

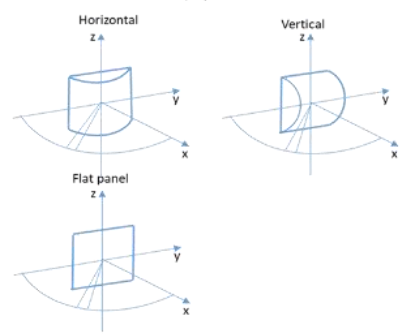

(c)

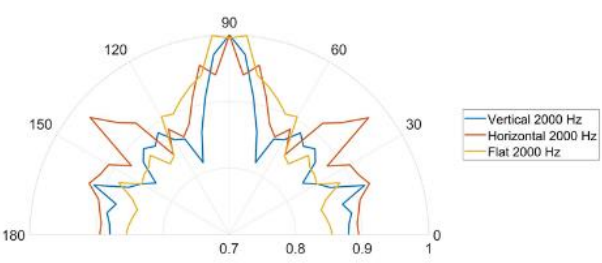

(b)

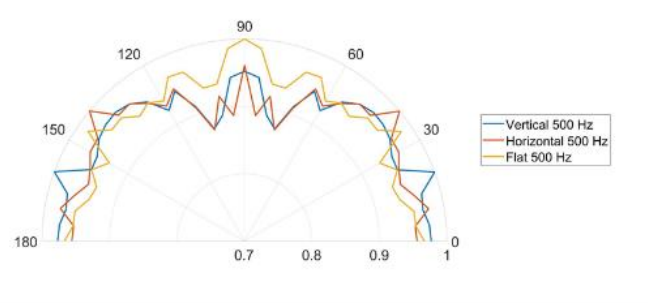

(d)

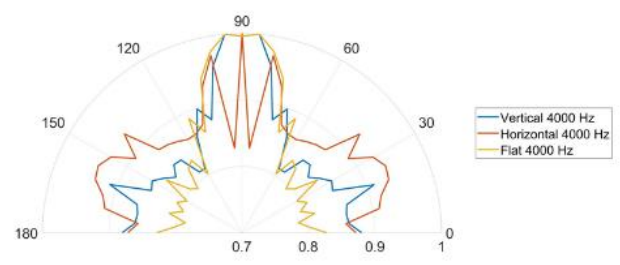

Figure 11. Diffusion characteristics for one diffuser related to the coordinate system defined in (a) for the diffusers mounted vertically and horizontally, as well as for a flat panel, for the frequencies $500 \mathrm{~Hz}(\mathbf{b}), 2000 \mathrm{~Hz}$ (c), and $4000 \mathrm{~Hz}(\mathbf{d})$.

The diffusers have resonance absorption properties at the lower frequencies [1]. The absorption properties of the diffusers were evaluated from measurements when only diffusers were mounted in the classroom. The diffuse sound field was assumed as the room was empty apart from the diffusers. The absorption properties were calculated using Sabine's formula. The evaluation shows that the diffusers contribute with absorption in frequencies $125-500 \mathrm{~Hz}$ with the highest contribution at $125 \mathrm{~Hz}$. These properties are independent of the diffuser orientation. The effect of this absorption in a room will be related to the amount of diffusers used.

The diffusers do not have specific directional scattering properties at these low frequencies. At the higher frequencies, the diffusers do have directional scattering effects, which are dependent on the orientation of the diffusers. This can be shown in terms of $A_{s c}$ calculated by using Equation (4). The $A_{s c}$ includes both absorption and scattering effects. The absorption together with the total equivalent scattering absorption area, $A_{s c}$, exemplified for 12 diffusers, vertically and horizontally oriented, can be seen in Figure 12 . The graph shows the same value for the two different orientations in terms of absorption. The different scattering properties, in terms of $A_{s c}$, show the orientation dependency for the higher frequency range. In the case of vertical diffusers, sound waves directed toward the ceiling have a larger effect on the $A_{s c}$ compared to the horizontally oriented diffusers. 
For the latter, sound waves are still dispersed but are mainly redirected in the horizontal plane and consequently not directed to an absorbent surface. Since $A_{s c}$ accounts for both absorption and scattering, the $A_{s c}$ value is lower for the horizontally oriented diffusers in the higher frequency area, which is where the diffuser affects the sound field the most.

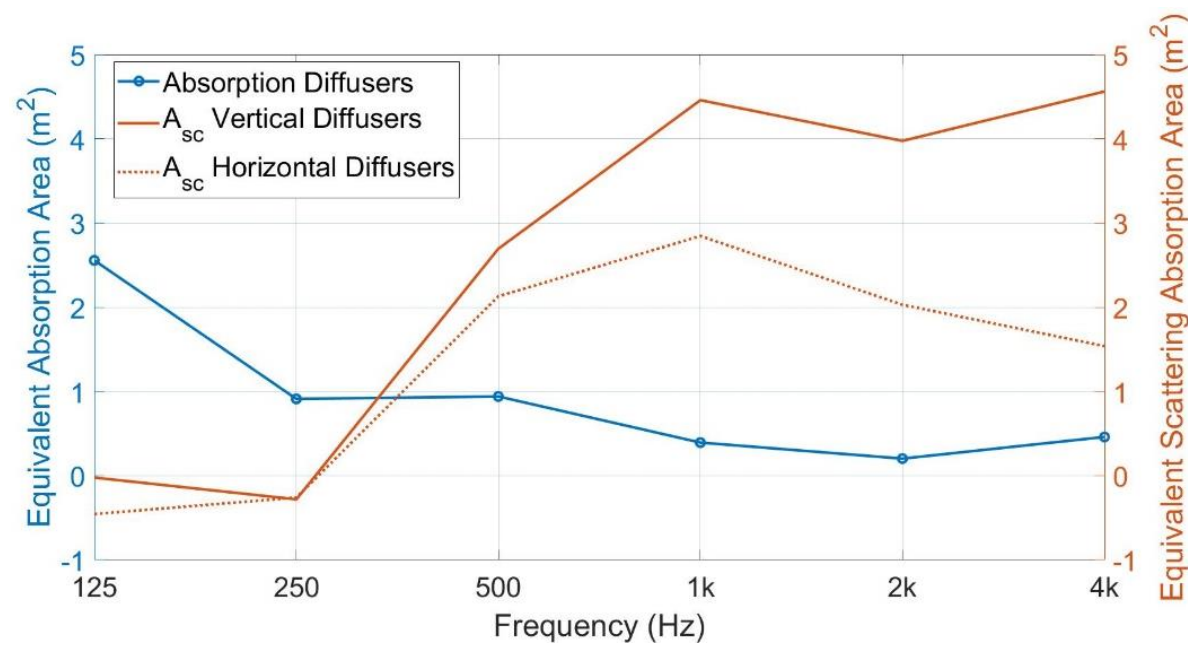

Figure 12. The graph shows the results for the cases of 12 diffusers mounted in rows; in each row, the diffusers are connected to each other. Left axis: Equivalent absorption area for the diffusors. Note: this absorption is independent of the diffusor orientation. Right axis: Equivalent scattering absorption area, $A_{s c}$, for vertically, VD, and horizontally, $\mathrm{HD}$, oriented diffusers.

\subsection{Configurations}

Starting from the absorbent ceiling only, diffusers were added in steps of 2 diffusers per wall, with up to 12 diffusers per wall being used. For example, see Figure 13. The addition of diffusers was performed for both vertically oriented and horizontally oriented diffusers.

In the cases of 8 and 12 diffusers, two different patterns were used, which were connected or separated. In the connected pattern, the diffusers were mounted in rows but connected to each other in each row, i.e., connected on two sides. In the separated pattern, denoted SEP, each diffusing element was free on all sides. For example, see Figure 14.
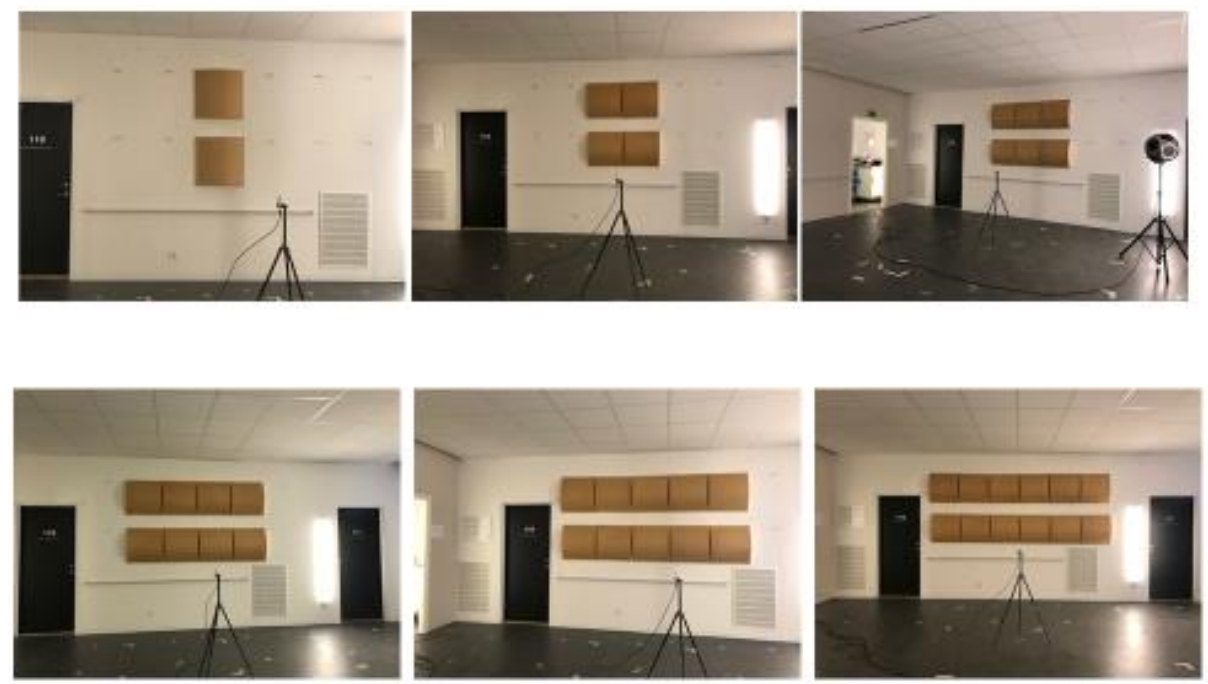

Figure 13. Example of configurations from two diffusers/wall, four diffusers in total. Two diffusers per wall were added up to the maximum number of 12 diffusers per wall, 24 diffusers in total. In this example, the case of vertically oriented diffusers is depicted. 


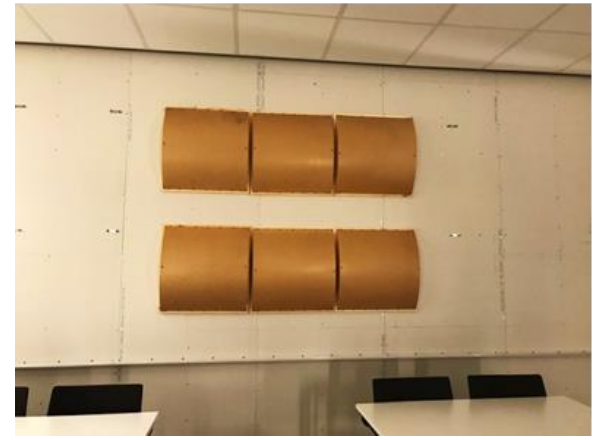

(a)

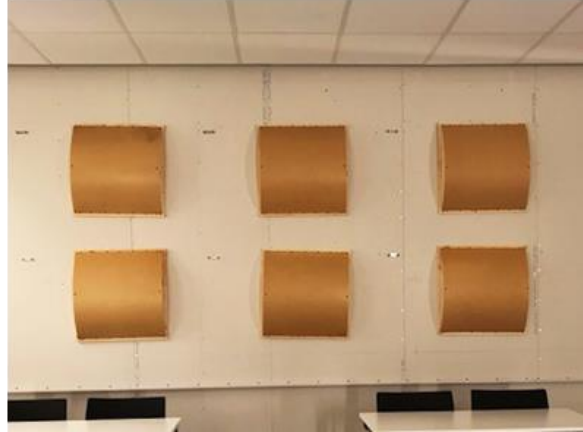

(b)

Figure 14. The mounting patterns connected (a) and separated (b) and, in this case, for configuration with vertically oriented diffusers (six diffusers per wall, i.e., 12 diffusers in total. (a) corresponds to configuration with description CA_F_12VD, and (b) corresponds to CA_F_12VD_SEP.

In a second step, furniture was added to all the configurations to evaluate whether the effect per diffusing element differed due to furnishings.

The same set-up of diffusers was always used for two adjacent walls; see Figure 15. All configurations are described in Table 1. The left part of the table shows configurations without furniture and the right part of the table shows corresponding configurations with furniture.

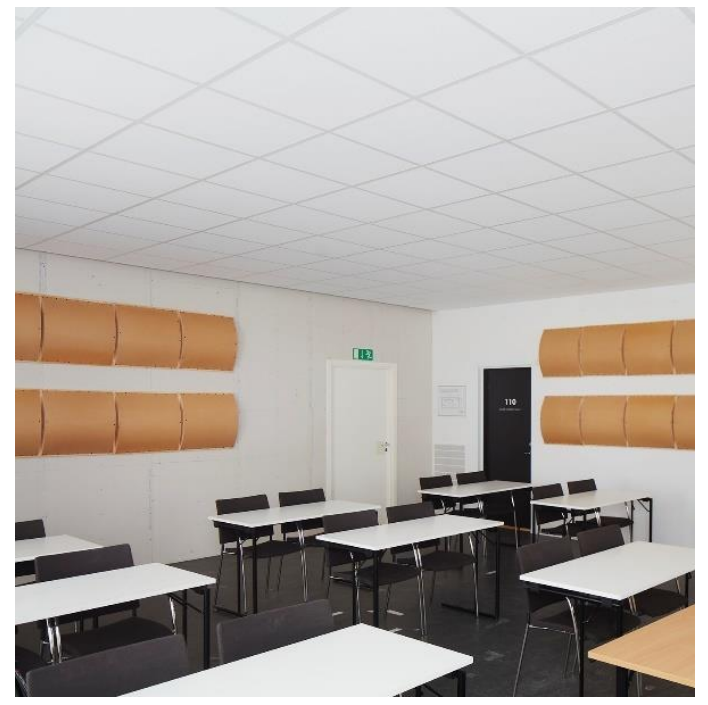

Figure 15. Diffusers, in all configurations, were mounted on two adjacent walls, as shown in this image. In each configuration, the same set-up was always used for the two walls.

Table 1. Configurations with absorbent ceiling used in the study, with configurations without furniture to the left and with furniture to the right.

\begin{tabular}{cccccc}
\hline Conf. & $\begin{array}{c}\text { Conf. } \\
\text { Abbreviation }\end{array}$ & Configuration Description & Conf. & $\begin{array}{c}\text { Conf. } \\
\text { Abbreviation }\end{array}$ & $\begin{array}{c}\text { Configuration } \\
\text { Description }\end{array}$ \\
\hline 1 & CA & $52 \mathrm{~m}^{2}$ Ceiling absorbers & 18 & CA_F & Conf $1+$ furniture \\
\hline 2 & CA_4VD & Conf $1+4$ vertical diffusers & 19 & CA_F_4VD & Conf $2+$ furniture \\
\hline 3 & CA_4HD & Conf $1+4$ horizontal diffusers & 20 & CA_F_4HD & Conf 3 + furniture \\
\hline 4 & CA_8VD_SEP & Conf $1+8$ vertical diffusers, separated & 21 & CA_F_8VD_SEP & Conf $4+$ furniture \\
\hline 5 & CA_8VD & Conf $1+8$ vertical diffusers, connected & 22 & CA_F_8VD & Conf 5 + furniture \\
\hline 6 & CA_8HD_SEP & Conf $1+8$ horizontal diffusers, separated & 23 & CA_F_8HD_SEP & Conf 6 + furniture \\
\hline
\end{tabular}


Table 1. Cont.

\begin{tabular}{cccccc}
\hline Conf. & $\begin{array}{c}\text { Conf. } \\
\text { Abbreviation }\end{array}$ & Configuration Description & Conf. & $\begin{array}{c}\text { Conf. } \\
\text { Abbreviation }\end{array}$ & $\begin{array}{c}\text { Configuration } \\
\text { Description }\end{array}$ \\
\hline 7 & CA_8HD & Conf $1+8$ horizontal diffusers, connected & 24 & CA_F_8HD & Conf $7+$ furniture \\
\hline 8 & CA_12VD_SEP & Conf $1+12$ vertical diffusers, separated & 25 & CA_F_12VD_SEP & Conf $8+$ furniture \\
\hline 9 & CA_12VD & Conf $1+12$ vertical diffusers, connected & 26 & CA_F_12VD & Conf 9 + furniture \\
\hline 10 & CA_12HD_SEP & Conf $1+12$ horizontal diffusers, \\
separated & 27 & CA_F_12HD_SEP & Conf 10 + furniture \\
\hline 11 & CA_12HD & Conf $1+12$ horizontal diffusers, \\
connected & 28 & CA_F_12HD & Conf 11 + furniture \\
\hline 12 & CA_16VD & Conf $1+16$ vertical diffusers, connected & 29 & CA_F_16VD & Conf 12 + furniture \\
\hline 13 & CA_16HD & $\begin{array}{c}\text { Conf } 1+16 \text { horizontal diffusers, } \\
\text { connected }\end{array}$ & 30 & CA_F_16HD & Conf 13 + furniture \\
\hline 14 & CA_20VD & Conf $1+20$ vertical diffusers, connected & 31 & CA_F_20VD & Conf 14 + furniture \\
\hline 15 & CA_20HD & $\begin{array}{c}\text { Conf } 1+20 \text { horizontal diffusers, } \\
\text { connected }\end{array}$ & 32 & CA_F_20HD & Conf 15 + furniture \\
\hline 16 & CA_24VD & Conf $1+24$ vertical diffusers, connected & 33 & CA_F_24VD & Conf 16 + furniture \\
\hline 17 & CA_24HD & $\begin{array}{c}\text { Conf } 1+24 \text { horizontal diffusers, } \\
\text { connected }\end{array}$ & 34 & CA_F_24HD & $\begin{array}{c}\text { Conf 17 + } \\
\text { Furniture }\end{array}$ \\
\hline
\end{tabular}

\subsection{Measurements}

The room acoustic parameters evaluated were reverberation time $\left(T_{20}\right)$ and speech clarity $\left(C_{50}\right)$, which were defined according to Equation (5) below. Measurements were performed using a DIRAC system (DIRAC type 7841, Ver.6.0). An exponential sweep signal was used as excitation. An omnidirectional loudspeaker with dodecahedron geometry was used. The center of the loudspeaker was $1.55 \mathrm{~m}$ from the floor. An omnidirectional microphone was used as a receiver $1.20 \mathrm{~m}$ from the floor. The loudspeaker and microphone used in the measurements can be seen in Figure 16.

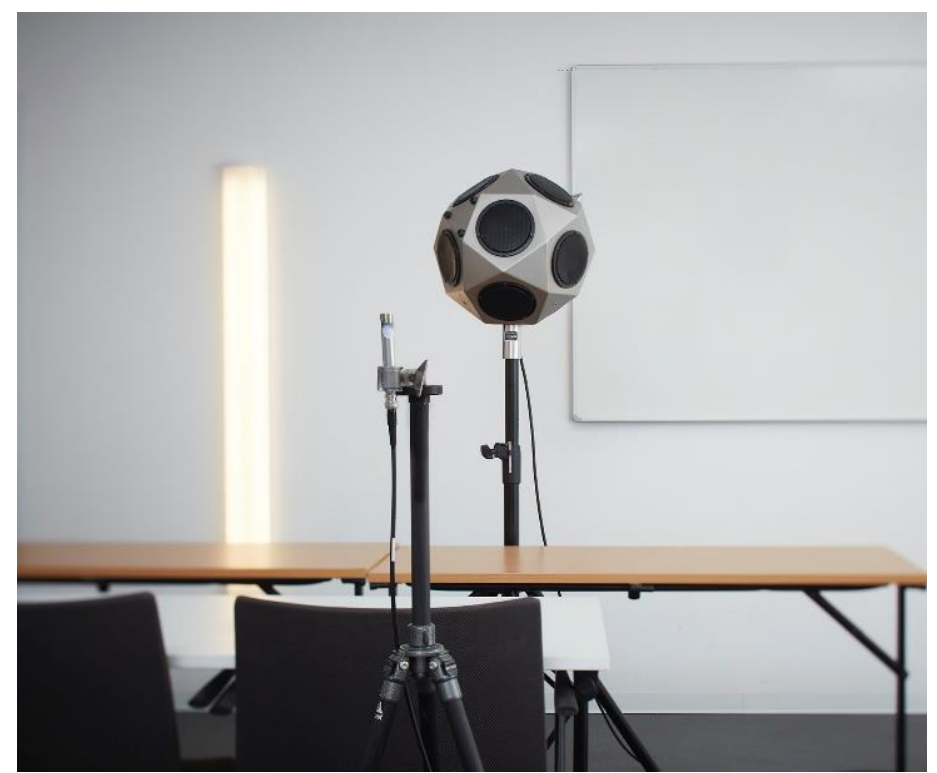

Figure 16. Loudspeaker and microphone used in the room acoustic measurements. The loudspeaker had its center at $1.50 \mathrm{~m}$ from the floor. The microphone was placed at a height of $1.20 \mathrm{~m}$ from the floor. 
Two source positions and six receiver positions were used. The positions in the room are seen in Figure 17.

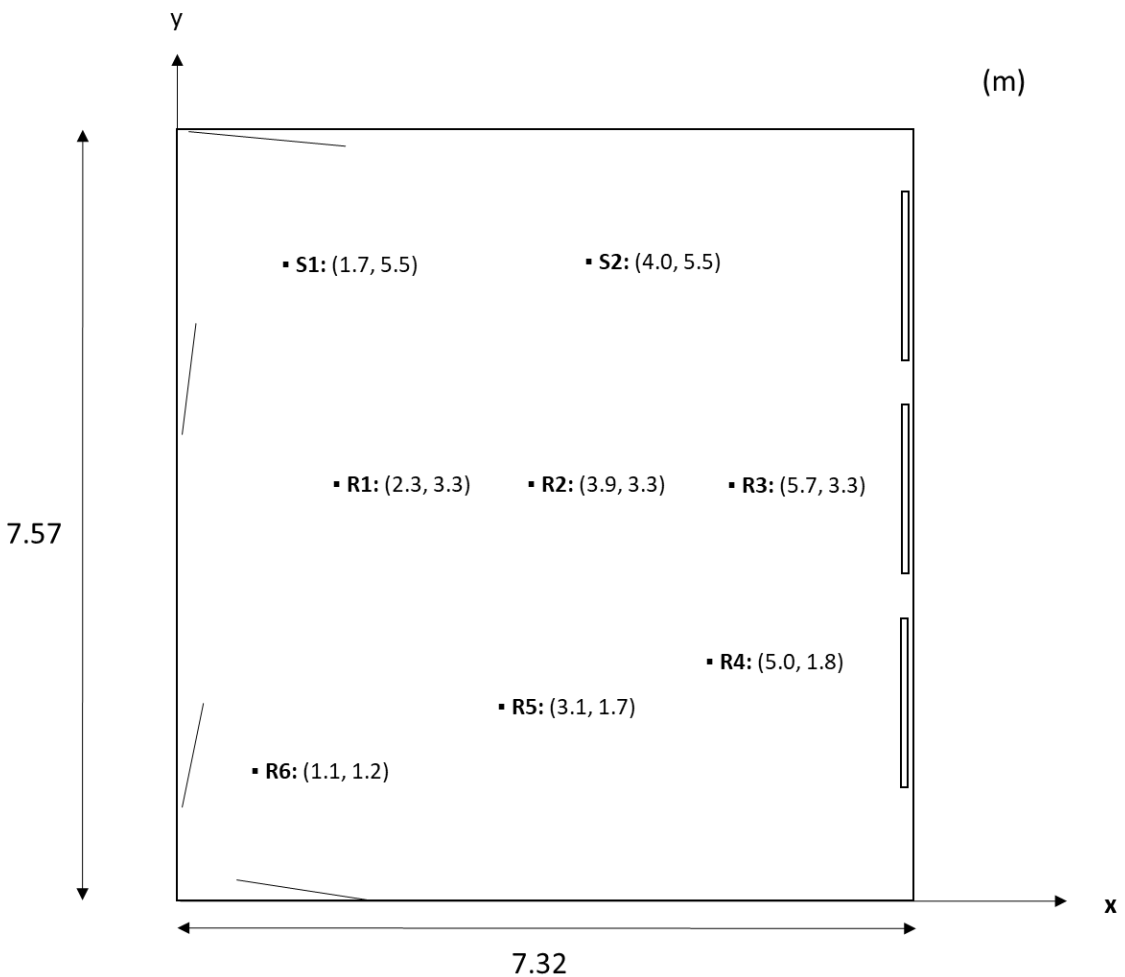

Figure 17. The dimensions of the classroom where measurements were performed. The source positions S1 and S2 can be seen as well as the six receiver positions R1-R6.

The reverberation time evaluated from the measurement was used in the analysis of $A_{s c}$ using Equation (4). In addition, speech clarity, $C_{50}$, was evaluated to investigate whether this room acoustic parameter could be related to $A_{s c}$ values.

Speech clarity $C_{50}$ is defined as

$$
C_{50}=10 \log \left(\frac{\int_{0}^{50 m s} h^{2}(t) d t}{\left.\int_{50 m s}^{\infty} h^{2}(t) d t\right)}\right)(\mathrm{dB})
$$

where $h(t)$ is the impulse response.

In speech clarity, early reflections are included. When evaluating $T_{20}$, according to ISO 3382-2 [44], the evaluation interval is -5 to $-25 \mathrm{~dB}$, given that the early reflections are excluded. The evaluation concerns octave bands in the range 125-4000 Hz, which were averaged over source and microphone positions.

In a previous study, repeatability was evaluated [1]. The repeatability interval for a 95\% confidence interval is shown in Table 2.

Table 2. Interval of repeatability for the room acoustic measurements performed in the classroom.

\begin{tabular}{ccc}
\hline & $\mathbf{T}_{\mathbf{2 0} \text {,avg }}$ (s) & $\mathbf{C}_{\mathbf{5 0 , a v g}}(\mathbf{d B})$ \\
\hline $125 \mathrm{~Hz}$ & \pm 0.077 & \pm 0.56 \\
$250 \mathrm{~Hz}$ & \pm 0.018 & \pm 0.29 \\
$500 \mathrm{~Hz}$ & \pm 0.010 & \pm 0.29 \\
$1000 \mathrm{~Hz}$ & \pm 0.006 & \pm 0.27 \\
$2000 \mathrm{~Hz}$ & \pm 0.010 & \pm 0.38 \\
$4000 \mathrm{~Hz}$ & \pm 0.008 & \pm 0.36 \\
\hline
\end{tabular}




\section{Results}

The following sections present the principal results from the study with a selection of the configurations representing the trends. However, all configurations shown in Table 1 were evaluated, and complete results can be found in Appendix A.

\subsection{Equivalent Scattered Absorption Area Depending on the Orientation and Quantity of Diffusers}

The equivalent scattering absorption area, $A_{s c}$, calculated by using Equation (4), derived above, varied significantly depending on the diffuser orientation; i.e., the diffusing characteristics change. This difference is seen at the higher frequencies where the diffusing elements are most effective as diffusers. In the lower frequency range, the diffusing elements have resonance absorption properties. The difference in diffusing characteristics starts at $1000 \mathrm{~Hz}$ and increases with increased frequency. At $2000 \mathrm{~Hz}$ and $4000 \mathrm{~Hz}$, the difference between vertically and horizontally oriented diffusers is significant. Results for 12 and 24 diffusers, mounted connected to each other in rows, are shown in Figure 18. However, the same differences are obtained for the pattern "separated" (see Appendix A).

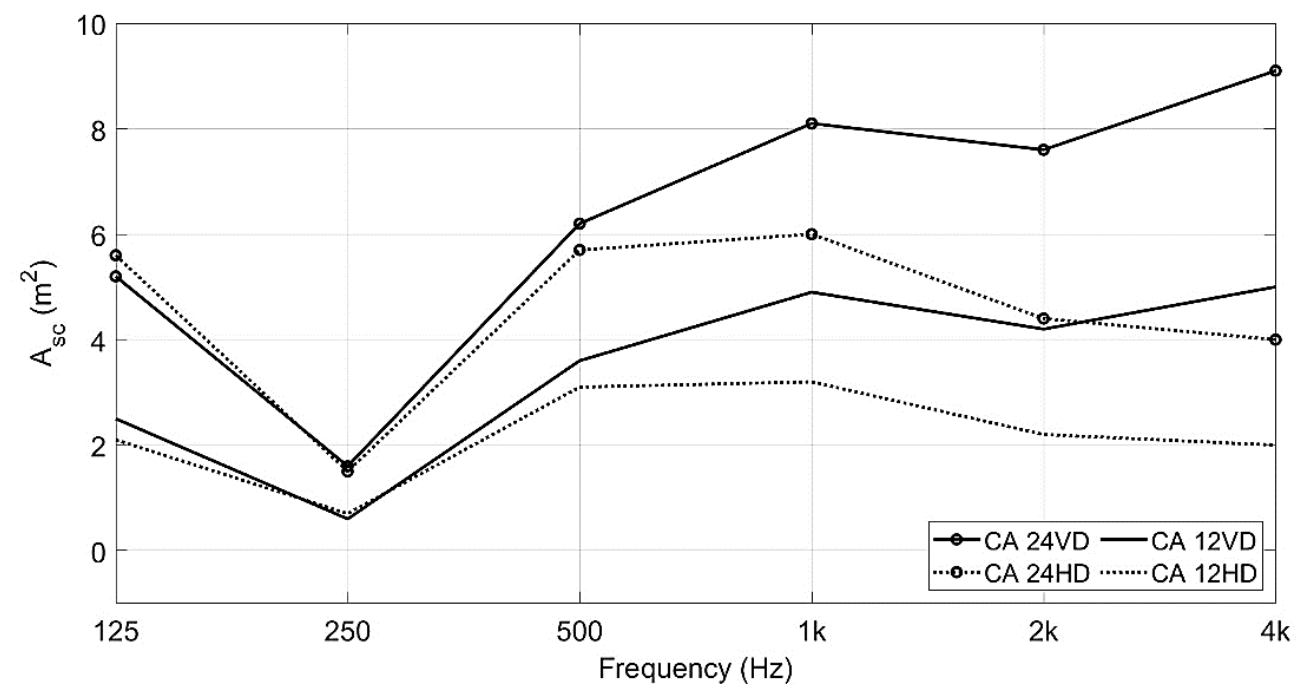

Figure 18. Comparison of the effect for vertically (denoted VD) and horizontally (denoted HD) oriented diffusers. The diffusers are mounted connected to each other in rows for all the configurations demonstrated in this graph.

Evaluating the quantity of diffusers showed a trend of lower effect in equivalent scattering absorption area per element when increasing the quantity of diffusers. This is valid for both vertically and horizontally oriented diffusers. The results in effect per element are shown in Figure 19.

\subsection{Effect of Diffuser Mounting Pattern}

Evaluation of the effect that the pattern had on scattering showed a greater effect when the diffusers were mounted separately from each other, instead of connected. This applies to both vertically and horizontally oriented diffusers. Figure 20 shows the scattering effect depending on pattern. The results presented in the graph show the effect per element, which was calculated from configurations using 12 diffusers. The configurations ending with "SEP" correspond to the pattern with diffusers mounted separately from each other, as shown in Figure 14b. 


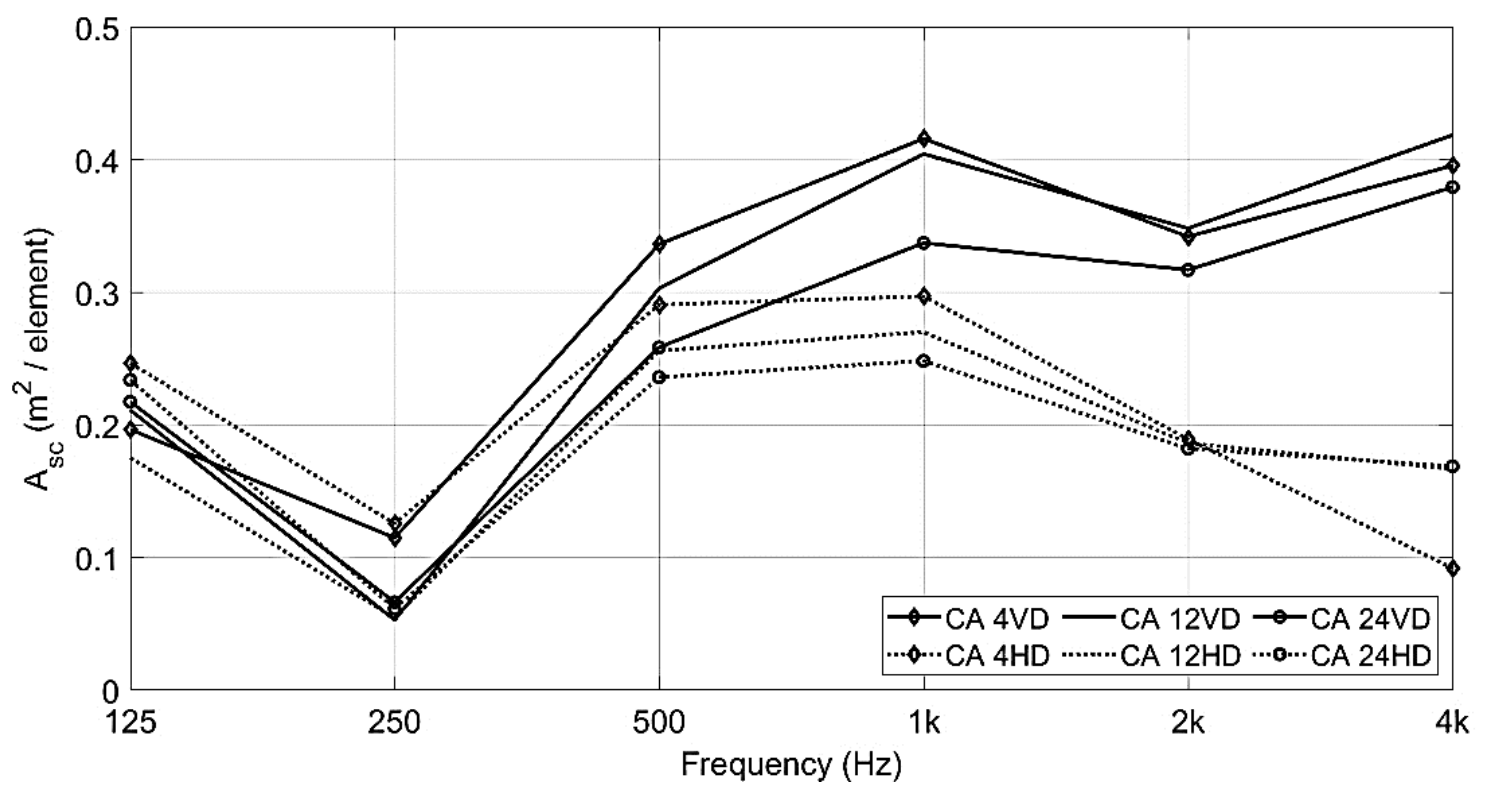

Figure 19. Effect per element for vertically oriented diffusers when a different quantity of diffusers is used. Configurations with 12 and 24 diffusers are demonstrated in this figure. The diffusers are mounted connected to each other in rows.

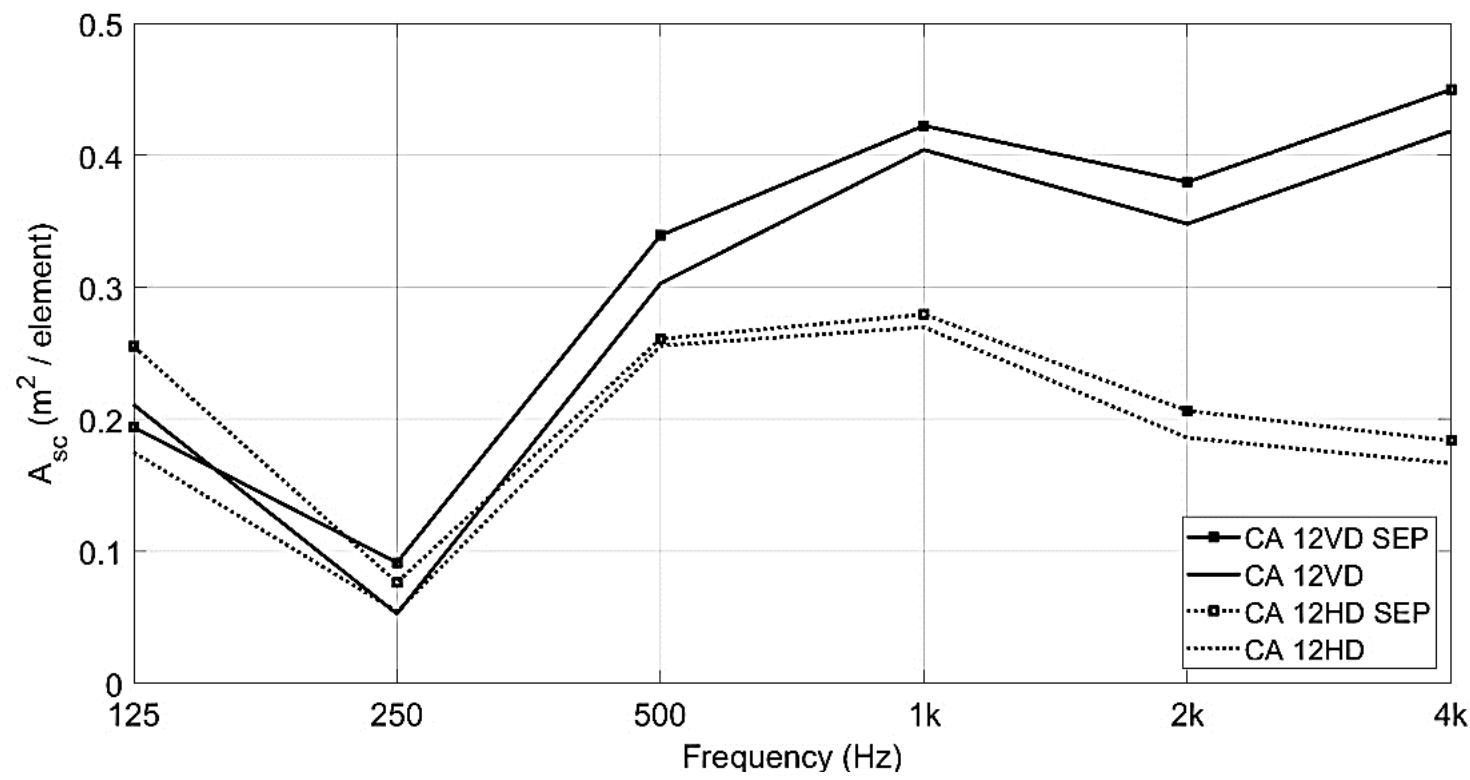

Figure 20. Equivalent scattering absorption area, $A_{s c}$, per diffuser for two different installation patterns. The graph shows results for 12 diffusers. The index "SEP" corresponds to the case when diffusers are installed separately from each other. The vertically oriented diffusers are denoted VD, and horizontally oriented diffusers are denoted HD.

\subsection{The Effect of Combining Diffusers and Furniture}

Combining diffusers and furniture (furniture set-up as in Figure 5) gives an additional effect in terms of the equivalent scattering absorption area, $A_{s c}$. The $A_{s c}$ is shown in Figure 21 for configurations with 12 diffusers, vertically (VD) and horizontally (HD), with furniture $(\mathrm{F})$ and without furniture. The figure shows a significant increase in equivalent scattering absorption area when furniture is added. The diffusers in the configurations demonstrated in the figure are mounted connected to each other in rows; however, the same trends are seen for diffusers mounted in pattern "separated" (see Appendix A). 


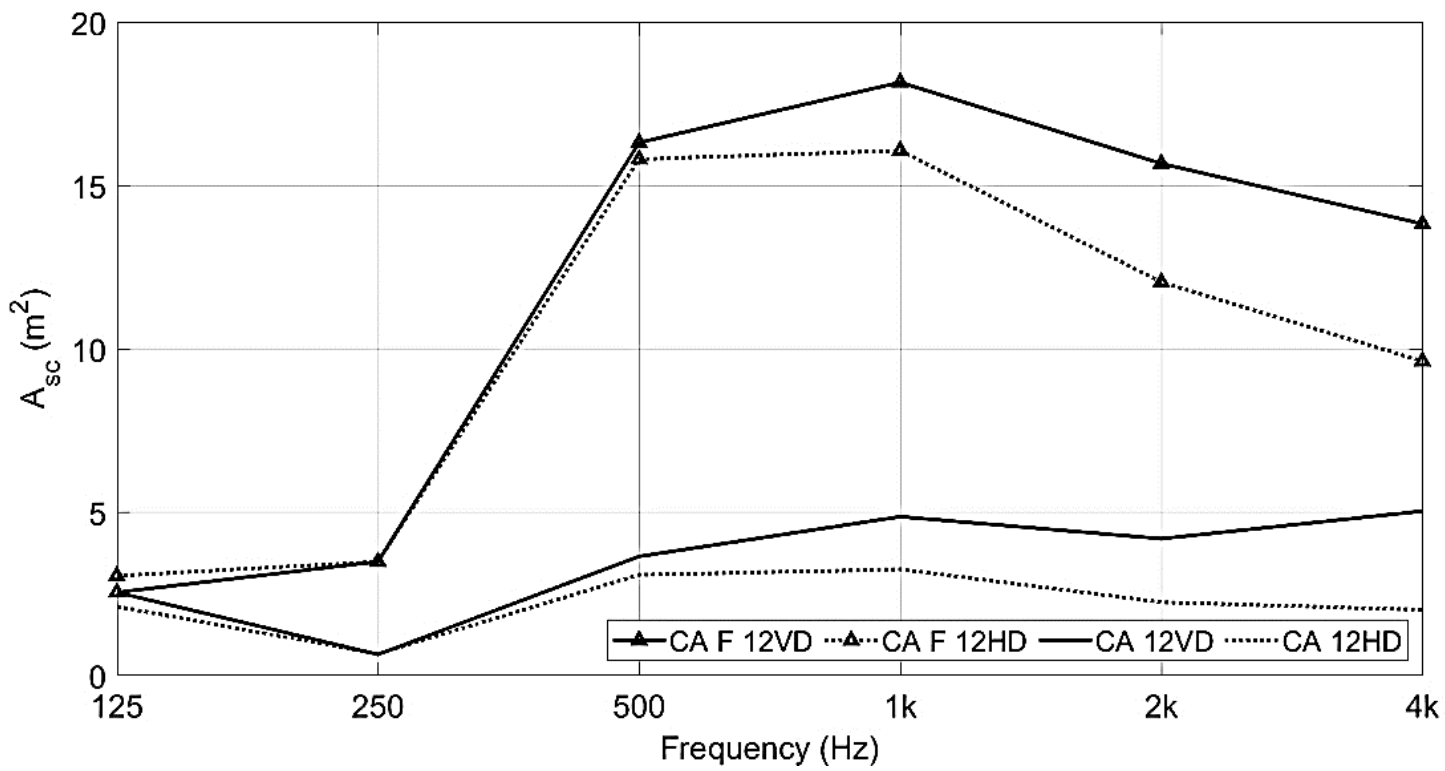

Figure 21. The $A_{s c}$ relating to the diffusers with furniture (F) and without furniture. Vertically oriented (VD) and horizontally oriented (HD) diffusers. A significant increase in $A_{s c}$ is seen when furniture is added. The diffusers are mounted connected to each other in rows in the configurations demonstrated in this figure.

Investigation of the effect of the combination of furniture and diffusers showed that the use of these different objects together provided an additional effect in terms of $A_{s c}$. Addition of the separate contribution in $A_{s c}$ for each type of object, i.e., diffusers and furniture, gives a lower total value than that measured for frequencies $2000-4000 \mathrm{~Hz}$. This is valid for both horizontally and vertically oriented diffusers. The effect of each type of object, i.e., diffusers and absorbers when measured separately and combined, as well as calculation of adding the two separate contributions, can be seen in Figure 22a (vertically oriented diffusers) and (b) (horizontally oriented diffusers). The diffusers are mounted connected to each other in rows for the configurations demonstrated in the figures.

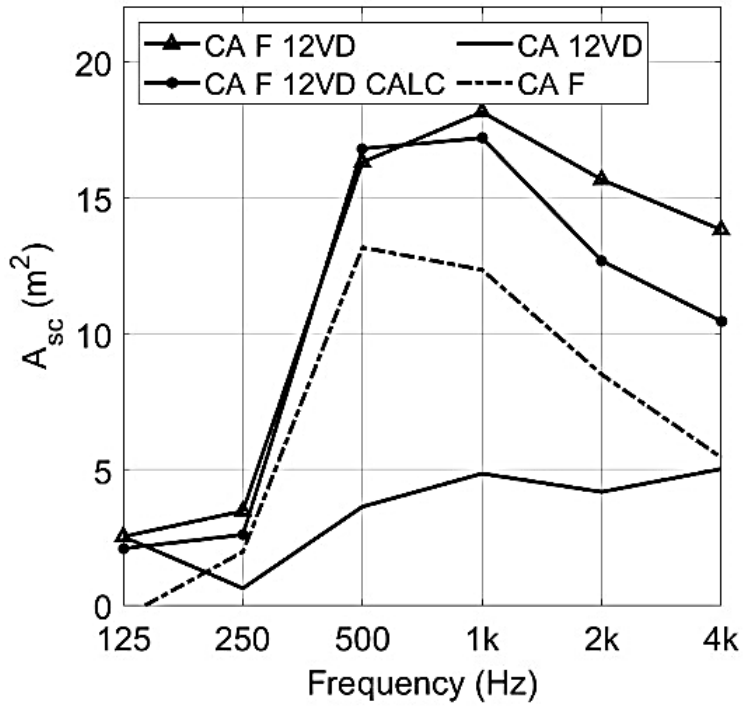

(a)

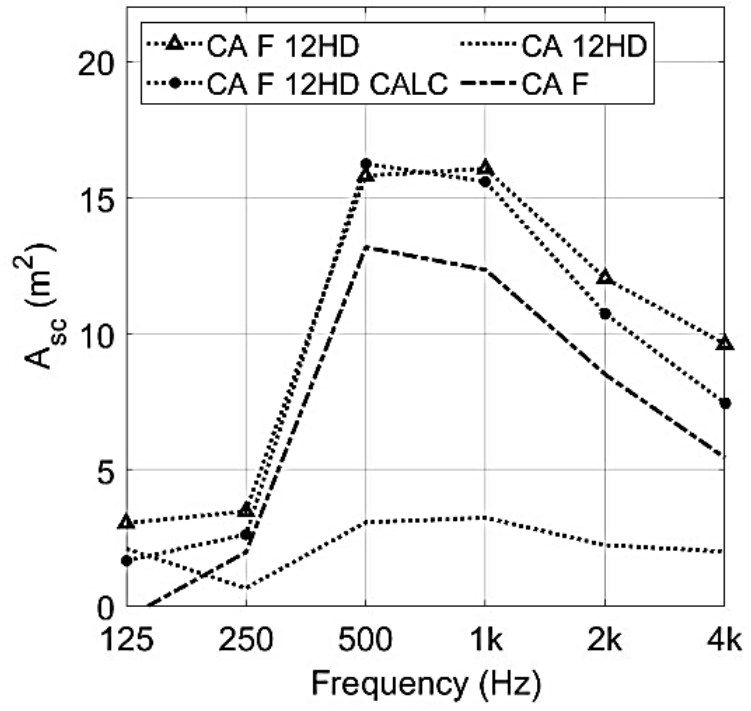

(b)

Figure 22. The effect on $A_{s c}$ of configuration with furniture (CA_F) and 12 diffusers, vertically oriented (a) and horizontally oriented (b). Adding (calculated) the contribution for the two separate objects diffusers and furniture is denoted "CALC". $A_{s c}$ from measured values, CA_F_12VD/12HD shows higher values than the separate contribution to $A_{s c}$; i.e., an additional effect on $A_{s c}$ is achieved when combining furniture and diffusers. 


\subsection{Effect on Room Acoustic Parameters}

Investigating the different configurations of diffusers with room acoustic parameters shows a relation between those parameters and $A_{s c}$. The higher scattering effect using vertically oriented diffusers resulted in a lower reverberation time, $T_{20}$, and higher speech clarity, $C_{50}$, compared to configurations with horizontally oriented diffusers. The two different patterns, separated and connected, where separated gave higher $A_{s c}$, which also showed a greater effect on the room acoustical parameters. Figure 23 shows $T_{20}$ and $C_{50}$ for a configuration with furniture, CA_F, the lowest quantity of diffusers, CA_F_4VD, the horizontally oriented diffusers, CA_F_12HD, and the vertically oriented diffusers, CA_F_12VD, which furthermore can be compared with the other pattern, CA_F_12VD_SEP. The scattering effects evaluated in previous sections affect the room acoustic parameters with the same trends; for example, a greater effect is seen when the diffusers are separated compared to connected as well as a greater effect for vertically oriented compared to horizontally oriented diffusers. Furthermore, it is shown that the room acoustic properties are similar at frequencies $125-500 \mathrm{~Hz}$ when the same number of diffusers are used, as the diffusers do not scatter at these low frequencies. The effect from absorption is dependent on how many absorbing elements are used, thereby the $T_{20}$ lowered as the number of diffusers increased.

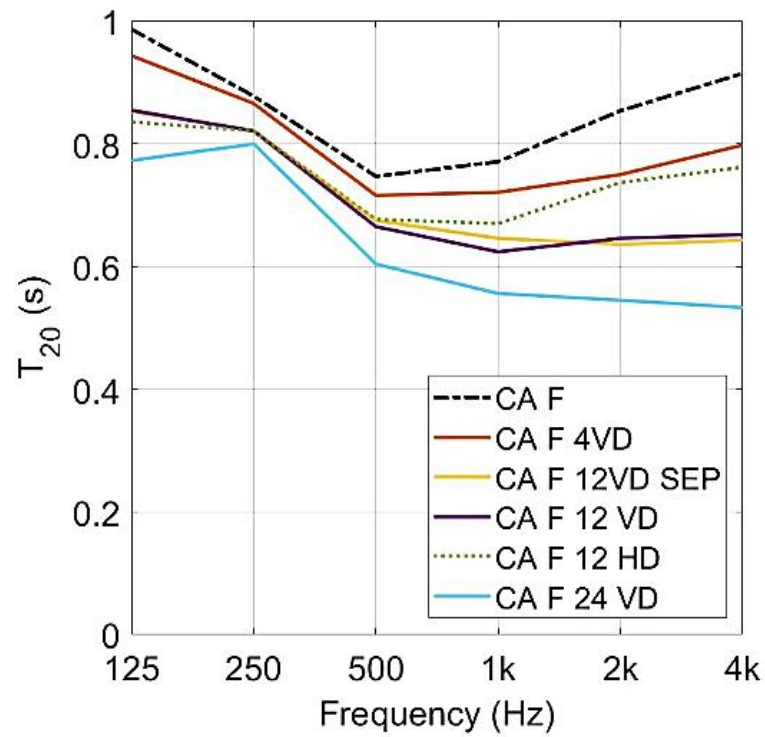

(a)

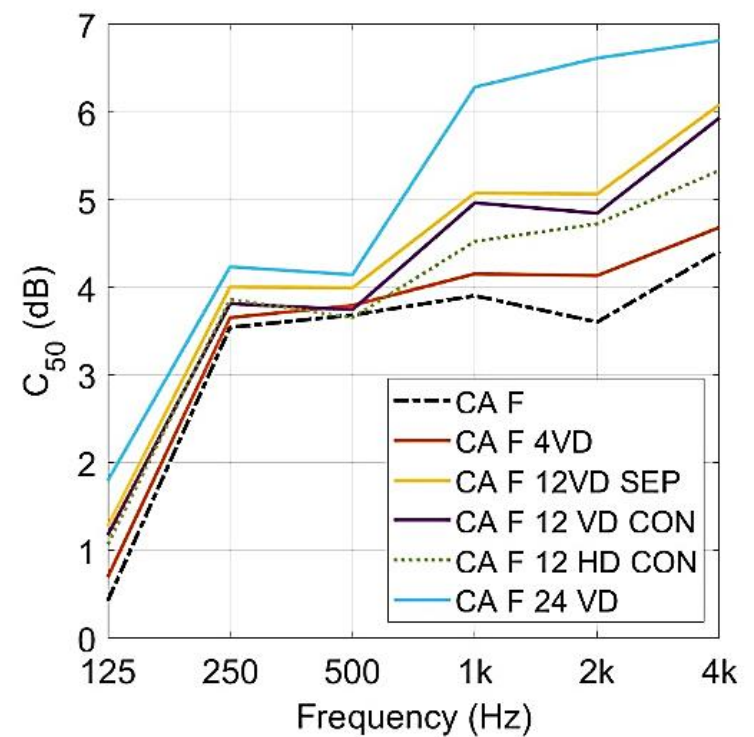

(b)

Figure 23. $T_{20}(\mathbf{a})$ and $C_{50}(\mathbf{b})$ for configurations with furniture. Configurations with varied numbers of diffusers, installation pattern, and orientation.

An evaluation of the relation between the equivalent scattered absorption area and room acoustic parameters shows a dependency on the $A_{s c}$ for the room acoustical parameters investigated. One example is shown in Figure 24 where the results for all configurations measured with furniture and vertically oriented diffusers are shown.

\section{5. $A_{s c}$ in Classroom Mock-Up versus Reverberation Chamber}

The effects of the diffusers in the classroom mock-up and in a reverberation chamber were compared. Twelve diffusers were used in vertical as well as horizontal orientation in the two different environments. In both cases, the diffusers were mounted connected to each other in rows. 
Values in the same range in terms of $A_{s c}$ per element were obtained for the two different environments. The results at the lowest frequency deviate, where the measurement in the reverberation chamber resulted in a lower $A_{s c}$ compared to the classroom measurement. This could be explained by the small dimension of the reverberation chamber. However, the fact that the same trends are found for the two environments and that similar values are obtained for the higher frequency range indicates that it can be possible to quantify the effect of the diffusers in a smaller, laboratory environment. The comparison of the effect on $A_{s c} /$ element for the two different environments can be found in Figure 25.
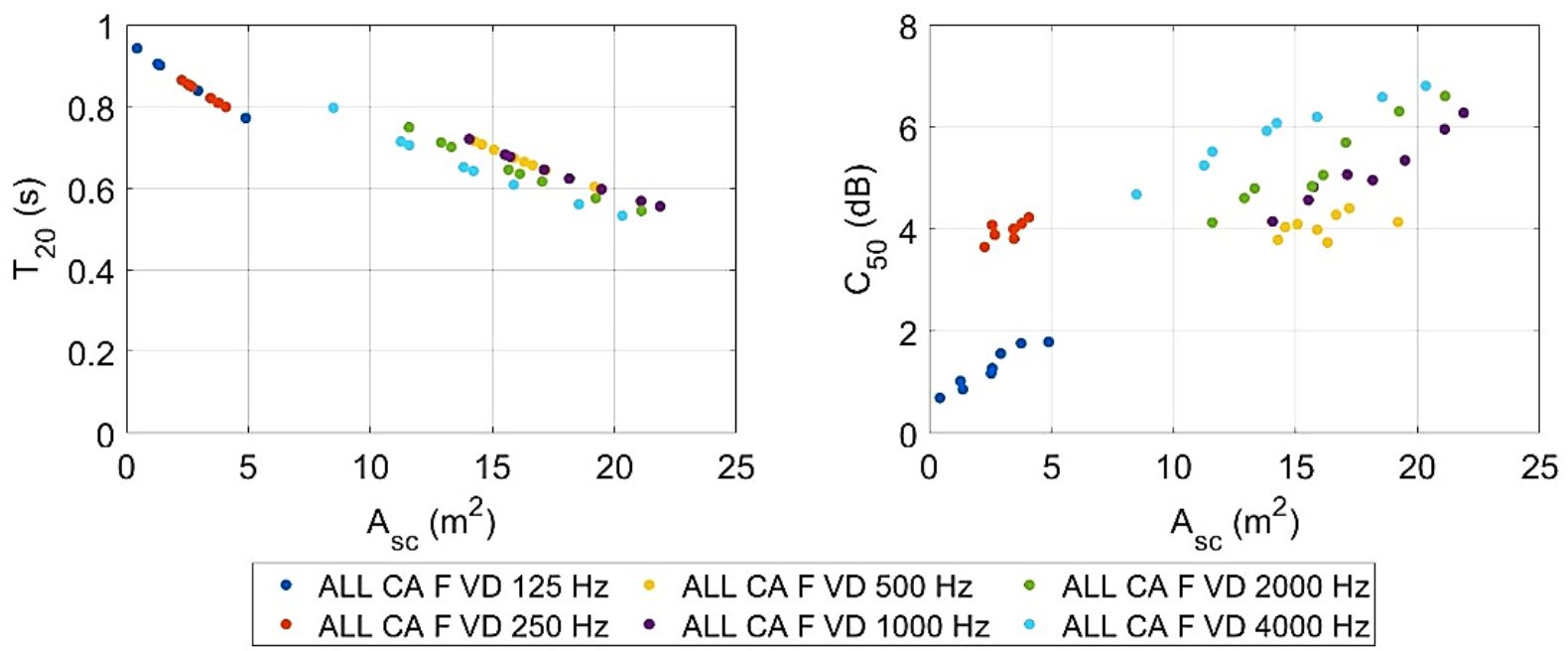

Figure 24. Relation between $A_{s c}$ and room acoustical parameters $T_{20}$ and $C_{50}$ for all configurations with vertically oriented diffusers, furniture, and absorbent ceiling.

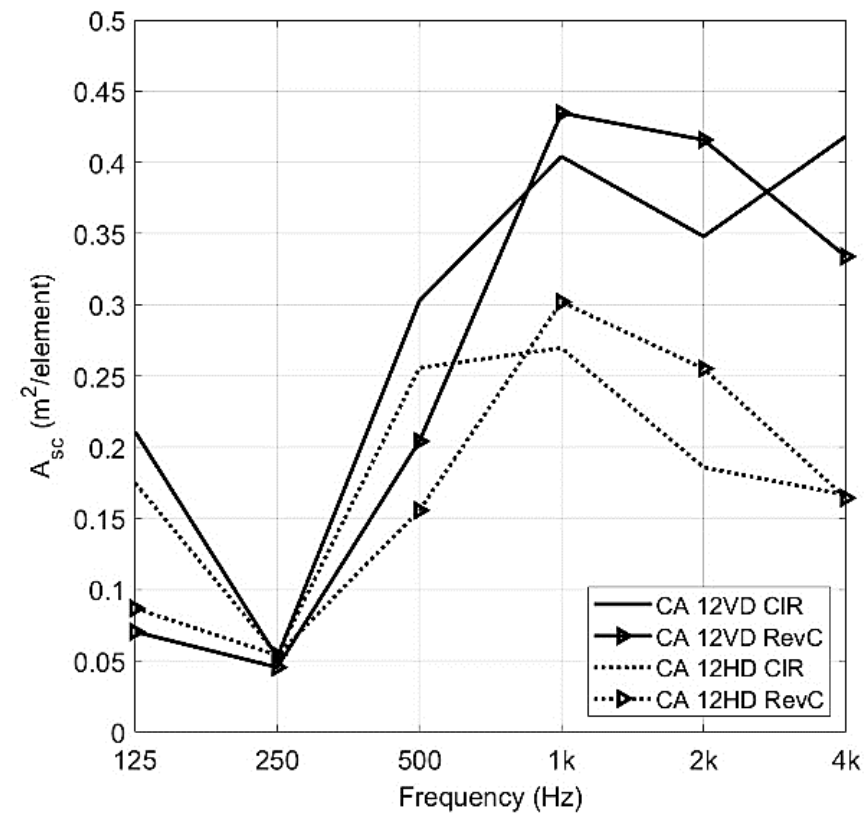

Figure 25. Effect in terms of $A_{s c}$ per element for measurement in a classroom mock-up (ClR) and reverberation chamber $(\operatorname{RevC})$ showing that the values obtained from the different environments are in the same range. The diffusers were mounted connected to each other in rows. 


\section{Discussion}

The aim of this study has been to investigate whether the measure $A_{s c}$ is sensitive enough to be used as an estimation of how the diffusers affect scattering and absorption in a room with absorbent ceiling and, if so, it could further be used in the SEA model from which the $A_{s c}$ originates to estimate room acoustic parameters.

The evaluation of the different orientations, i.e., vertically and horizontally, giving different diffusing characteristics, showed significant differences in scattering. These results are obtained due to the fact that there is an absorbent ceiling installed, which is a typical treatment in ordinary rooms. The absorption of the diffusers, low frequency in this case, is independent of orientation yet related to the quantity of diffusers.

The scattering effect per element decreased with a greater number of diffusers; however, the total scattering in the room must of course be considered in the acoustic design, as scattering still increased with the addition of more diffusers. Whether there is a limit of when the effect of additional diffusers can be neglected has not been investigated in this case.

With different patterns, the effect per element differed, with more scattering in pattern "SEP", where the elements are separated from each other; all sides of the diffusers are exposed in this pattern. Thus, the pattern of the installation of diffusers is an aspect to be considered in acoustic design. For ordinary rooms, on which this study is focusing, the space available for acoustic treatment is often limited, and thus, the most effective placement can be particularly important for such environments.

Adding furniture further increased the effect; the total scattering was not only due to the addition of the two different types of objects, but an extra effect could be seen that also had an impact on the room acoustical parameters. This additional effect was seen at the higher frequencies where the diffusing properties are the greatest but also where the absorption from the ceiling and furniture contributes most. In this investigation, one set-up of furniture has been investigated: a furnishing that could be described as sparse. Due to the extra effect seen on $A_{s c}$ when combining the two types of objects, i.e., diffusers and furniture, it would be of interest to investigate the effect when using a denser furnishing set-up.

Altogether, $A_{s c}$ could be related to the variation of diffuser configurations. Investigating the $A_{s c}$ in relation to room acoustic parameters showed a dependency: with higher $A_{s c}$, the $T_{20}$ decreased and $C_{50}$ increased. In this case, two room acoustic parameters were investigated, in the work going forward, other parameters, such as STI, could be investigated as well.

The aspects described above show how $A_{s c}$ is a parameter sensitive to changes in diffuser set-ups, but in order to use the model for the estimation of acoustic parameters, the $A_{s c}$ for a diffuser must be quantified beforehand. For this purpose, the $A_{s c}$ values obtained in full-scale classroom were compared to those obtained in a reverberation chamber. Similar values are seen for the high frequencies, while a deviation is obtained in the lower frequency range. This deviation can be due to the small scale of the reverberation room. However, the comparison indicated a possibility of quantifying the diffusers in a laboratory environment. Thus, to establish such a method of transforming data from laboratory environment scale to full scale, a number of aspects must be defined for the test room such as the absorption properties of the ceiling, number of elements to be used, and volume of the room. The findings on the decreased effect per element and its installation pattern should be accounted for, and further, the interaction between furniture and diffusers must be considered in the calculation model.

An absorbent ceiling is a good baseline as regards the room acoustics for these types of rooms, with additional treatment such as diffusers being a good complement. The fact that these elements can be designed to operate either as scattering objects, diffusing elements with specific directivity properties, or as absorbers in a specified and limited frequency makes this type of treatment suitable in the fine tuning of the acoustic design, also in environments such as ordinary public rooms. 
In future applications, using this model would allow architects and other practitioners to get estimations of how the use of diffusers in an ordinary room affects the room's acoustic properties. The fast results obtained from a calculation model, compared to simulation models, would give the opportunity to test several different designs of diffusers and set-up patterns of diffusers within a limited timeframe. The possibility to include these elements, as well as other acoustic treatments, already in the design phase increases the possibility of achieving good acoustics, and good aesthetics, in the final room.

\section{Conclusions}

It has been found in this study that the effect of diffusers installed in a mock-up of a classroom with a sound-absorbing ceiling could be quantified by calculating the equivalent scattering absorption area, $A_{s c}$. The $A_{s c}$ value is defined on the basis of a two-system SEA model where the sound field is subdivided into a grazing and non-grazing part. The $A_{s c}$ is related to the coupling loss factor between the two sub-systems. A relation between $A_{s c}$ values, the quantity of diffusers, their orientation, and their installation pattern has been obtained. The $A_{s c}$ /element decreased with the number of diffusers. Higher effects in terms of the $A_{s c}$ /element were seen for vertically oriented diffusers, i.e., when the diffusers direct sound to the ceiling. In patterns where all sides of the diffusers were exposed, the effect of the $A_{s c}$ /element was higher compared to when the diffusers were mounted direct to each other. The evaluation also showed that the combination of diffusers and furniture increased the effect on $A_{s c}$ by more than the separate contribution of each type of object.

In addition, a dependency between $A_{s c}$ and the room acoustic parameters reverberation time $T_{20}$, and speech clarity, $C_{50}$, can be seen. The variation in the $A_{s c} /$ element due to the pattern, amount, and orientation as well as the effect of furniture was reflected in the room acoustic parameters measured. Thus, the $A_{s c}$ measure could be an appropriate way of quantifying the effect of the diffusers, taking the above-mentioned design aspects of the diffusers and its installation into account.

Furthermore, it was seen that quantification in terms of $A_{s c}$ of the diffusers obtained in a reverberation chamber with absorbent ceiling treatment gave similar values as in the classroom measurement. This indicates that the quantification of diffusers in terms of $A_{s c}$ is possible in a laboratory environment. In the work going forward, for applying this method in real cases, the test procedure must be defined. The effect per element depending on the number of diffusers and installation pattern is to be included, and further, the combined effect of diffusers and furniture must be considered. Applying the model would support fast estimations of the room acoustic properties when different designs of the treatment are evaluated and thereby increase the possibility of achieving good room acoustics in ordinary rooms.

Author Contributions: Writing—original draft preparation: E.A.; Experiments—design and accomplishment: E.A. and E.N.; Experiments—analysis: E.A.; Structure of paper and supervision: E.N., O.J.I.K. and D.B.H. All authors have read and agreed to the published version of the manuscript.

Funding: This research is funded by Saint-Gobain Ecophon.

Data Availability Statement: The data presented in this study are available on request from the corresponding author.

Acknowledgments: The authors are grateful for the support from Ecophon providing material, laboratory equipment, and laboratory facilities making it possible to perform the experiments.

Conflicts of Interest: The authors declare no conflict of interest. 


\section{Abbreviations}

Acoustic Configurations

CA

$\mathrm{F}$

VD

HD

SEP

CALC

CIR

RevC
Ceiling absorptive

Furniture, the room is sparsely furnished

Vertical diffusers

Horizontal diffusers

Separated diffuser pattern

Calculated values

Classroom

Reverberation chamber

\section{Appendix A}

Table A1. Complete results, measurements of $T_{20}$ and $C_{50}$ as well as $A_{s c}$ values.

\begin{tabular}{|c|c|c|c|c|c|c|c|c|c|c|}
\hline & & $\mathrm{CA}$ & CA_4VD & CA_8VD_SEP & CA_8VD & CA_12VD_SEP & CA_12VD & CA_16VD & CA_20VD & CA_24VD \\
\hline \multirow{31}{*}{ T20 } & Frequency [Hz] & Avg & Avg & Avg & Avg & Avg & Avg & Avg & Avg & Avg \\
\hline & 125 & 0.965 & 0.928 & 0.886 & 0.891 & 0.863 & 0.855 & 0.84 & 0.793 & 0.763 \\
\hline & 250 & 0.966 & 0.944 & 0.924 & 0.951 & 0.915 & 0.936 & 0.926 & 0.911 & 0.894 \\
\hline & 500 & 1.549 & 1.396 & 1.276 & 1.29 & 1.163 & 1.195 & 1.157 & 1.083 & 1.029 \\
\hline & 1000 & 1.545 & 1.361 & 1.218 & 1.218 & 1.094 & 1.108 & 1.058 & 0.976 & 0.932 \\
\hline & 2000 & 1.382 & 1.257 & 1.142 & 1.151 & 1.038 & 1.06 & 1.011 & 0.93 & 0.89 \\
\hline & \multirow[t]{2}{*}{4000} & 1.24 & 1.124 & 1.005 & 1.016 & 0.917 & 0.934 & 0.881 & 0.819 & 0.778 \\
\hline & & $\mathrm{CA}$ & CA_4HD & CA_8HD_SEP & CA_8HD & CA_12HD_SEP & CA_12HD & CA_16HD & CA_20HD & CA_24HD \\
\hline & Frequency [Hz] & Avg & Avg & Avg & Avg & Avg & Avg & Avg & Avg & Avg \\
\hline & 125 & 0.965 & 0.919 & 0.876 & 0.896 & 0.835 & 0.872 & 0.834 & 0.784 & 0.751 \\
\hline & 250 & 0.966 & 0.942 & 0.923 & 0.944 & 0.923 & 0.935 & 0.934 & 0.913 & 0.899 \\
\hline & 500 & 1.549 & 1.415 & 1.307 & 1.3 & 1.234 & 1.239 & 1.174 & 1.101 & 1.06 \\
\hline & 1000 & 1.545 & 1.409 & 1.312 & 1.281 & 1.214 & 1.223 & 1.16 & 1.096 & 1.041 \\
\hline & 2000 & 1.382 & 1.31 & 1.237 & 1.24 & 1.171 & 1.189 & 1.148 & 1.094 & 1.049 \\
\hline & 4000 & 1.24 & 1.211 & 1.142 & 1.144 & 1.084 & 1.097 & 1.045 & 1.019 & 0.981 \\
\hline & & CA_F & CA_F_4VD & CA_F_8VD_SEP & CA_F_8VD & CA_F_12VD_SEP & CA_F_12VD & CA_F_16VD & CA_F_20VD & CA_F_24VD \\
\hline & Frequency [Hz] & Avg & Avg & Avg & Avg & Avg & Avg & Avg & Avg & Avg \\
\hline & 125 & 0.987 & 0.944 & 0.906 & 0.902 & 0.853 & 0.855 & 0.84 & 0.81 & 0.773 \\
\hline & 250 & 0.878 & 0.866 & 0.854 & 0.85 & 0.822 & 0.821 & 0.821 & 0.81 & 0.8 \\
\hline & 500 & 0.747 & 0.716 & 0.695 & 0.708 & 0.675 & 0.665 & 0.657 & 0.645 & 0.604 \\
\hline & 1000 & 0.771 & 0.721 & 0.678 & 0.683 & 0.646 & 0.624 & 0.598 & 0.569 & 0.556 \\
\hline & 2000 & 0.854 & 0.75 & 0.702 & 0.713 & 0.636 & 0.646 & 0.617 & 0.576 & 0.545 \\
\hline & \multirow[t]{2}{*}{4000} & 0.915 & 0.798 & 0.715 & 0.706 & 0.643 & 0.652 & 0.609 & 0.561 & 0.533 \\
\hline & & CA_F & CA_F_4HD & CA_F_8HD_SEP & CA_F_8HD & CA_F_12HD_SEP & CA_F_12HD & CA_F_16HD & CA_F_20HD & CA_F_24HD \\
\hline & Frequency [Hz] & Avg & Avg & Avg & Avg & Avg & Avg & Avg & Avg & Avg \\
\hline & 125 & 0.987 & 0.923 & 0.893 & 0.89 & 0.852 & 0.836 & 0.824 & 0.789 & 0.754 \\
\hline & 250 & 0.878 & 0.875 & 0.845 & 0.85 & 0.833 & 0.821 & 0.816 & 0.813 & 0.794 \\
\hline & 500 & 0.747 & 0.734 & 0.699 & 0.695 & 0.677 & 0.677 & 0.659 & 0.629 & 0.635 \\
\hline & 1000 & 0.771 & 0.734 & 0.711 & 0.715 & 0.676 & 0.67 & 0.643 & 0.631 & 0.622 \\
\hline & 2000 & 0.854 & 0.804 & 0.767 & 0.766 & 0.719 & 0.737 & 0.7 & 0.682 & 0.663 \\
\hline & 4000 & 0.915 & 0.86 & 0.81 & 0.799 & 0.757 & 0.762 & 0.729 & 0.705 & 0.686 \\
\hline
\end{tabular}


Table A1. Cont.

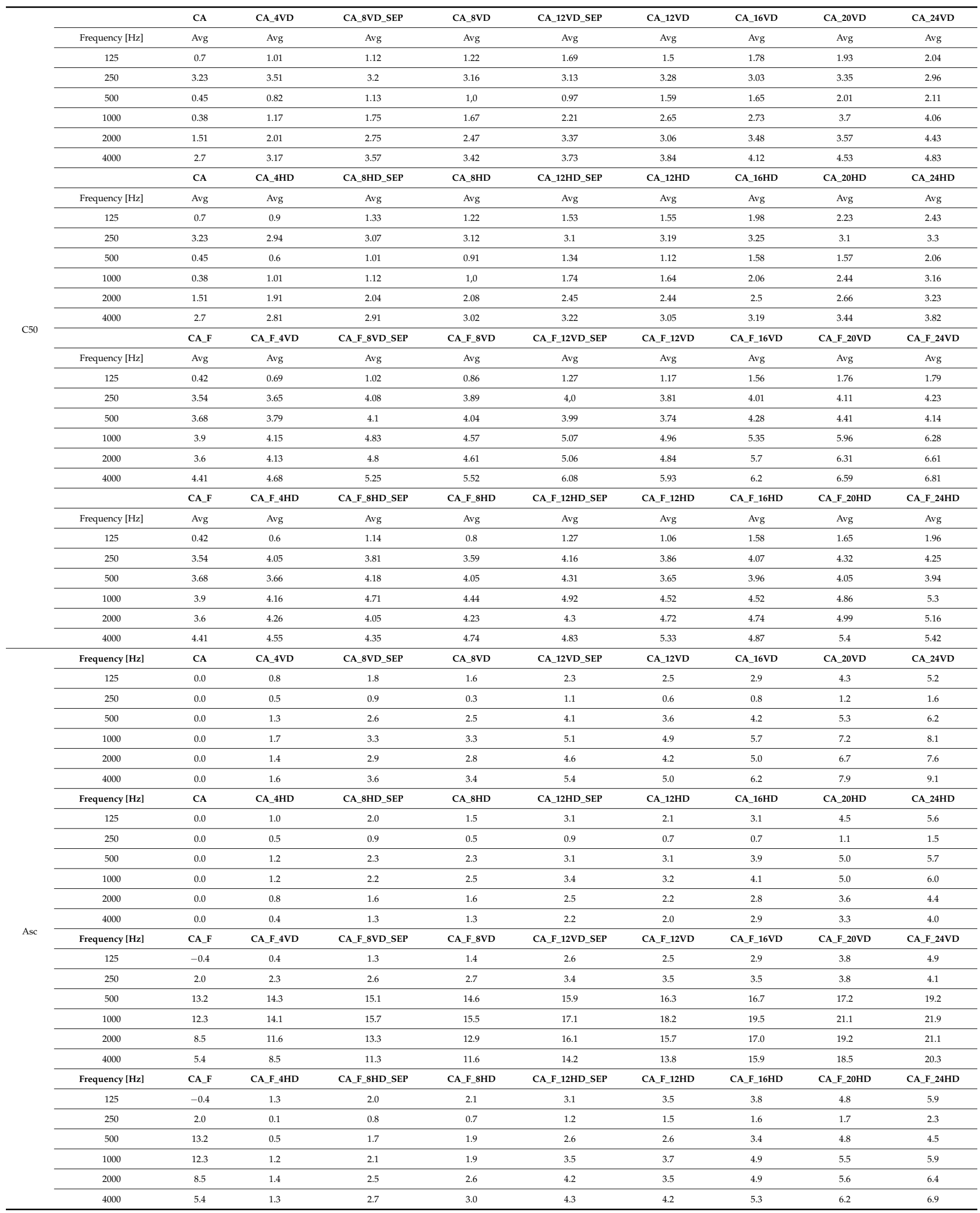




\section{References}

1. Arvidsson, E.; Nilsson, E.; Bard Hagberg, D.; Karlsson, O.J.I. The effect on room acoustical parameters using a combination of absorbers and Diffusers-An experimental study in a classroom. Acoustics 2020, 2, 505-523. [CrossRef]

2. Arvidsson, E.; Nilsson, E.; Bard Hagberg, D.; Karlsson, O.J.I. The difference in subjective experience related to acoustic treatments in an ordinary public room: A case study. Acoustics 2021, 3, 442-461. [CrossRef]

3. Erling, N.; Emma, A. An energy model for the calculation of room acoustic parameters in rectangular rooms with absorbent ceilings. Appl. Sci. 2021, 11, 6607.

4. Lochner, J.P.A.; Burger, J.F. The influence of reflections on auditorium acoustics. J. Sound Vib. 1964, 1, 426-454. [CrossRef]

5. Bradley, J.S.; Sato, H.; Picard, M. On the importance of early reflections for speech in rooms. J. Acoust. Soc. Am. 2003, 113, 3233-3244. [CrossRef]

6. Sato, H.; Morimoto, M.; Wada, M. Relationship between listening difficulty rating and objective measures in reverberant and noisy sound fields for young adults and elderly persons. J. Acoust. Soc. Am. 2012, 131, 4596-4605. [CrossRef]

7. Sato, H.; Bradley, J.S.; Morimoto, M. Using listening difficulty ratings of conditions for speech communication in rooms. J. Acoust. Soc. Am. 2005, 117, 1157-1167. [CrossRef]

8. Sato, H.; Bradley, J. Evaluation of acoustical conditions for speech communication in working elementary school classrooms. $J$. Acoust. Soc. Am. 2008, 123, 2064-2077. [CrossRef]

9. Yang, W.; Bradley, J. Effects of room acoustics on the intelligibility of speech in classrooms for young children. J. Acoust. Soc. Am. 2009, 125, 922-933. [CrossRef]

10. Sato, H.; Morimoto, M.; Sato, H.; Wada, M. Relationship between listening difficulty and acoustical objective measures in reverberant sound fields. J. Acoust. Soc. Am. 2008, 123, 2087-2093. [CrossRef]

11. Puglisi, G.E.; Prato, A.; Sacco, T.; Astolfi, A. Influence of classroom acoustics on the reading speed: A case study on Italian second-graders. J. Acoust. Soc. Am. 2018, 144, 144-149. [CrossRef]

12. Bradley, J.S.; Reich, R.D.; Norcross, S.G. On the combined effects of signal-to-noise ratio and room acoustics on speech intelligibility. J. Acoust. Soc. Am. 1999, 106, 1820-1828. [CrossRef]

13. Barron, M.; Lee, L.-J. Energy relations in concert auditoriums. I. J. Acoust. Soc. Am. 1988, 84, 618-628. [CrossRef]

14. Barron, M. Theory and measurement of early, late and total sound levels in rooms. J. Acoust. Soc. Am. 2015, 137, 3087-3098. [CrossRef] [PubMed]

15. Beranek, L. The sound strength parameter $\mathrm{G}$ and its importance in evaluating and planning the acoustics of halls for music. $J$. Acoust. Soc. Am. 2011, 129, 3020-3026. [CrossRef]

16. Kjellberg, A.; Ljung, R.; Hallman, D. Recall of words heard in noise. Appl. Cogn. Psychol. 2008, 22, 1088-1098. [CrossRef]

17. Ljung, R.; Kjellberg, A. Long reverberation time decreases recall of spoken information. Build. Acoust. 2009, 16, 301-311. [CrossRef]

18. Ljung, R.; Israelsson, K.; Hygge, S. Speech intelligibility and recall of spoken material heard at different signal-to-noise ratios and the role played by working memory capacity. Appl. Cogn. Psychol. 2013, 27, 198-203. [CrossRef]

19. Cucharero, J.; Hänninen, T.; Lokki, T. Influence of sound-absorbing material placement on room acoustical parameters. Acoustics 2019, 1, 644-660. [CrossRef]

20. Berardi, U.; Iannace, G.; Trematerra, A. Acoustic treatments aiming to achieve the Italian minimum environmental criteria (cam) standards in large reverberant. Can. Acoust. 2019, 47, 73-80.

21. Cucharero, J.; Hänninen, T.; Lokki, T. Angle-dependent absorption of sound on porous materials. Acoustics 2020, 2, 753-765. [CrossRef]

22. Nolan, M.; Verburg, S.A.; Brunskog, J.; Fernandez-Grande, E. Experimental characterization of the sound field in a reverberation room. J. Acoust. Soc. Am. 2019, 145, 2237-2246. [CrossRef] [PubMed]

23. Nolan, M. Estimation of angle-dependent absorption coefficients from spatially distributed in situ measurements. J. Acoust. Soc. Am. 2020, 147, 119-124. [CrossRef]

24. Cox, T.J.; D'Antonio, P. Acoustic Absorbers and Diffusers, 3rd ed.; Taylor \& Francis: Boca Raton, FL, USA, 2017.

25. Choi, Y.J. Effects of periodic type diffusers on classroom acoustics. Appl. Acoust. 2013, 74, 694-707. [CrossRef]

26. Choi, Y.J. The application of diffusers for classroom acoustical design. Noise Vib. Worldw. 2014, 45, 8-16. [CrossRef]

27. Choi, Y.J. An optimum combination of absorptive and diffusing treatments for classroom acoustic design. Build. Acoust. 2014, 21, 175-180. [CrossRef]

28. Choi, Y.J. Predicting classroom acoustical parameters for occupied conditions from unoccupied data. Appl. Acoust. 2017, 127, 89-94. [CrossRef]

29. Labia, L.; Shtrepi, L.; Astolfi, A. Improved room acoustics quality in meeting rooms: Investigation on the optimal configurations of sound-absorptive and sound-diffusive panels. Acoustics 2020, 2, 451-473. [CrossRef]

30. ISO. ISO 3382-1:2009. In Acoustics—Measurement of Room Acoustic Parameters_Part 1: Performance Spaces; ISO: Geneva, Switzerland, 2009.

31. Bradley, J.S.; Reich, R.; Norcross, S.G. A just noticeable difference in C50 for speech. Appl. Acoust. 1999, 58, 99-108. [CrossRef]

32. Visentin, C.; Pellegatti, M.; Prodi, N. Effect of a single lateral diffuse reflection on spatial percepts and speech intelligibility. J. Acoust. Soc. Am. 2020, 148, 122-140. [CrossRef] 
33. Shtrepi, L.; Di Blasio, S.; Astolfi, A. Listeners sensitivity to different locations of diffusive surfaces in performance spaces: The case of a shoebox concert hall. Appl. Sci. 2020, 10, 4370. [CrossRef]

34. Shtrepi, L.; Astolfi, A.; D'Antonio, G.; Guski, M. Objective and perceptual evaluation of distance-dependent scattered sound effects in a small variable-acoustics hall. J. Acoust. Soc. Am. 2016, 140, 3651-3662. [CrossRef] [PubMed]

35. Shtrepi, L.; Astolfi, A.; Puglisi, G.; Masoero, M. Effects of the distance from a diffusive surface on the objective and perceptual evaluation of the sound field in a small simulated variable-acoustics hall. Appl. Sci. 2017, 7, 224. [CrossRef]

36. Lyon, R.H.; De Jong, R.G. Theory and Application of Statistical Energy Analysis, 2nd ed.; RH Lyon Corp: Cambridge, MA, USA, 1998.

37. Vigran, T.E. Building Acoustics; Taylor \& Francis: New York, NY, USA, 2008.

38. Prodi, N.; Visentin, C. An experimental evaluation of the impact of scattering on sound field diffusivity. J. Acoust. Soc. Am. 2013, 133, 810-820. [CrossRef] [PubMed]

39. EN 12354-6:2004. Building Acoustics, Estimation of Acoustic Performance of Buildings from the Performance of Elements-Part 6: Sound Absorption in Enclosed Spaces; CEN: Brussels, Belgium, 2004.

40. Nilsson, E. Input data for acoustical design calculations for ordinary public rooms. In Proceedings of the 24th International Congress on Sound and Vibration, London, UK, 23-27 July 2017.

41. ISO. ISO 9053-2:2020 Acoustics-Determination of Airflow Resistance—Part 2: Alternating Airflow Method; ISO: Geneva, Switzerland, 2020.

42. ISO. ISO 354:2003: Acoustics. Measurement of Sound Absorption in a Reverberation Room; ISO: Geneva, Switzerland, 2003.

43. ISO. ISO 11654:1997 Acoustics—Sound Absorbers for Use in Buildings_-Rating of Sound Absorption; ISO: Geneva, Switzerland, 1997.

44. ISO. ISO 3382-2:2008 Acoustics-Measurements of Room Acoustic Parameters-Part 2: Reverberation Time in Ordinary Rooms; ISO: Geneva, Switzerland, 2008. 